\title{
OPEN Low-dose Drosera rotundifolia induces gene expression changes in 16HBE human bronchial epithelial cells
}

\author{
Fabio Arruda-Silva ${ }^{\bowtie}$, Paolo Bellavite \& Marta Marzotto
}

Drosera rotundifolia has been traditionally used for the treatment of respiratory diseases in phytotherapy and homeopathy. The mechanisms of action recognized so far are linked to the known effects of specific components, such as flavonoids, but are not completely understood. In this study, the biological functions of $D$. rotundifolia were explored in vitro following the treatment of bronchial epithelial cells, which are the potential targets of the pharmacological effects of the herbal medicine. To do so, the whole plant ethanolic extract was 1000 -fold diluted in water $(D$. rotundifolia $3 x$ ) and added to a 16HBE human cell line culture for $3 \mathrm{~h}$ or $6 \mathrm{~h}$. The effects on gene expression of the treatments and corresponding controls were then investigated by RNA sequencing. The differentially expressed genes were validated through RT-qPCR, and the enriched biological functions involved in the effects of treatment were investigated. $D$. rotundifolia $3 \times$ did not impair cell viability and was shown to be a stimulant of cell functions by regulating the expression of dozens of genes after $3 \mathrm{~h}$, and the effects were amplified after $6 \mathrm{~h}$ of treatment. The main differentially expressed genes encoded ligands of epithelial growth factor receptor, proteins involved in xenobiotic detoxification and cytokines, suggesting that $D$. rotundifolia $3 \times$ could stimulate self-repair systems, which are impaired in airway diseases. Furthermore, $D$. rotundifolia $3 \times$ acts on a complex and multifaceted set of genes and may potentially affect different layers of the bronchial mucosa.

Pathologies of the airways are among the most common diseases. Cough is a common complaint in patients of all ages, with air pollutants contributing to airway challenge. In children, cough is the second most common symptom of respiratory disease after runny nose, with a $46-56 \%$ prevalence depending on the age of the child. The use of pharmacological treatment without side effects could be useful not only to reduce cough symptoms but also to prevent the toxic effects of pollution. Low doses of plant-derived drugs are largely used for cold and cough symptoms in adults and children ${ }^{1-7}$. Often, these are used with the hope of resolving ailments not successfully cured by conventional drugs as a complementary treatment to reduce the consumption of anti-inflammatory drugs or steroids that may have adverse effects and to relieve certain symptoms and improve the quality of life. However, there is presently no definitive explanation for the possible biological activity of such preparations at the cellular level.

European sundew species (Drosera rotundifolia L., Drosera intermedia Hayne, and Drosera anglica Huds) have been used as traditional medicines in the therapy of respiratory tract infections. Drosera Herba, which is comprised chiefly of Drosera rotundifolia, has been commonly used for its spasmolytic properties in the treatment of convulsive or whooping cough since the seventeenth century. The general action on the respiratory system of $D$. rotundifolia was described in the homeopathic Materia Medica ${ }^{8}$ and includes profuse expectoration and a spasmodic, paroxysmal, dry, and irritative cough, similar to whooping cough, and the plant is often included as a component in homeopathic complexes used for upper respiratory tract ailments. The efficacy of such remedies for the relief of symptoms or the improvement of quality of life was analysed in clinical studies, which reported positive results ${ }^{5,9-12}$.

Ethanol extracts of Drosera species contain high concentrations of flavonoids (hyperoside, isoquercitrin, quercetin, and myricetin-3-O-galactoside) together with phenolic acids (ellagic acid) ${ }^{13}$. Flavonoids have been reported to have anti-inflammatory ${ }^{14}$, antioxidant and antimicrobial properties, which are efficacious in the treatment of respiratory diseases ${ }^{15}$. Traces of naphthoquinones were also found in some preparations ${ }^{16}$. 
Bronchial epithelial cells are specialized cells strictly connected to a tissue that form a barrier that protects against external agents of damage. Epithelial membrane integrity could be injured by pathogenic events that damage basal cellular activities (cell cycle, viability, energy balance and oxidative stress) or impair specific activities, such as the maintenance of the electrolytic balance (functioning of membrane ion channels) ${ }^{17-19}$. With appropriate stimulation, the bronchial epithelium can contribute to innate immunity by secreting immune-stimulatory and modulatory mediators, including cytokines, chemokines, growth factors, and lipid mediators that recruit and activate effector cells and antigen-presenting cells $\mathrm{s}^{20-22}$. Differentiated $16 \mathrm{HBE}$ cells simulate many of the activities of the bronchial epithelium and are considered a good model for basic studies.

The aim of this study was to evaluate the effect of a low homeopathic concentration of D. rotundifolia ethanolic extract on the transcriptome of the human bronchial epithelial cell line 16HBE. Transcriptomics, which is an important tool of functional genomics research, can be used to study overall gene expression and function, which could be the first step in revealing specific biological processes and molecular mechanisms that are involved in the occurrence of the disease. For this study, a D. rotundifolia third decimal $(3 \times)$ dilution was used (1000 times more diluted than the whole ethanolic extract). The $3 \times$ terminology corresponds to the traditional homeopathic nomenclature according to the Anglo-American convention ${ }^{23}$. The goal of the study was to discover the potential gene targets of $D$. rotundifolia $3 \times$ after 3 and $6 \mathrm{~h}$ of incubation by means of the RNA-seq technique. After validating the main genes using RT-qPCR, the main biological functions involved in D. rotundifolia $3 \times$ action were identified.

\section{Results}

Analysis of polyphenols in the $D$. rotundifolia ethanolic extract. The concentration of polyphenols in the D. rotundifolia ethanolic extract was estimated to be $7.1 \times 10^{-3} \mathrm{~mol} / \mathrm{L}$ in terms of the gallic acid equivalents. This concentration corresponds to approximately $1.2 \mathrm{mg} / \mathrm{mL}$ of total polyphenols, which in turn corresponds to a concentration of $12 \mu \mathrm{g} / \mathrm{mL}$ in the $D$. rotundifolia $3 \times$ test sample and $1.2 \mu \mathrm{g} / \mathrm{mL}\left(7.1 \times 10^{-6} \mathrm{~mol} / \mathrm{L}\right)$ in the final cell culture. The $D$. rotundifolia ethanolic extract was also qualitatively analysed by mass spectrometry. In the HPLC 6.590 min retention time peak, the mass spectrum showed peaks corresponding to ellagic acid $(\mathrm{m} / \mathrm{z}=300.997905)$ and isoquercitrin $(\mathrm{m} / \mathrm{z}=463.087935)$. In addition, at the $8.004 \mathrm{~min}$ retention time peak, quercetin $(\mathrm{m} / \mathrm{z}=301.035282)$ was detected. Regarding the presence of hyperoside, which has the same molecular mass as isoquercitrin, there is a chance that the isoquercitrin peak represented a mixture of both compounds. The results confirmed the presence of important bioactive components in D. rotundifolia ethanolic extract ${ }^{13}$.

Effect of $D$. rotundifolia $3 \times$ on $16 \mathrm{HBE}$ cell viability. The viability of the bronchial epithelial cells (16HBE) (Fig. 1) was not impaired after $3 \mathrm{~h}$ of exposure to D. rotundifolia $3 \times$ or the corresponding control (Ctrl), demonstrating the absence of cytotoxicity caused by the plant preparation at the dilutions used in the experiments. Furthermore, after $24 \mathrm{~h}$ of incubation with $D$. rotundifolia $3 \times$, the cells showed a small $(+6.9 \%)$ but significant $(p=0.019)$ increase in cell viability. No morphological changes or alteration of cell adherence to the bottom of the well could be observed by optical microscopic inspection (data not shown).

Changes in gene expression after $\boldsymbol{D}$. rotundifolia $3 \times$ treatment. The effects of $D$. rotundifolia $3 \times$ treatment on the global gene expression of $16 \mathrm{HBE}$ cells were investigated after $3 \mathrm{~h}$ of incubation by comparison with the control. The experiments were reproduced in 4 different biological replicates, and the gene expression profile in response to $D$. rotundifolia $3 \times$ treatment was investigated by RNA-seq analysis.

The reads obtained by the sequencing were quantified as transcripts by Salmon, which showed an average mapping coverage of $92 \%$. Differential gene expression analysis was then performed to identify the significant target genes of D. rotundifolia $3 \times$ treatment. The differential expression output obtained from DESeq 2 analysis displayed a total of 69 statistically significant (padj<0.05) differentially expressed genes (DEGs); 44 genes were upregulated (Table 1), and 25 genes were downregulated (Table 2). The lof2FoldChange ranged from +0.7 (maximum upregulation, Table 1) to - 0.51 (maximum downregulation, Table 2).

Gene ontology classification of differentially expressed genes. To better understand the functions of the identified genes, functional analysis was performed by submitting the up- and downregulated gene list to gene ontology (GO) enrichment analysis using the Bioconductor/R package gprofiler2. The representative enriched biological processes and the genes associated with these processes are represented in Table 3. The DEGs were mainly enriched in biological processes, including general functions such as "regulation of response to stimulus", which includes 34 of the 69 genes, and more specific biological activities, such as "vasculature development" (13 of 69 genes) and "positive regulation of vascular endothelial growth factor production" (5 of 69 genes). A group of 10 genes is associated with the function "epithelial cell proliferation". This gene set includes the upregulated gene LGR5 (a GPCR receptor protein and member of the Wnt signalling pathway that controls cell proliferation), the downregulated gene IGFBP3 (encoding insulin-like growth factor-binding protein 3 , which exerts anti-proliferative effects in many cell types) and 8 other genes with specific GO functions related to epithelial regulation (the upregulated epithelial growth factor-like ligands EREG and EPGN, the downregulated EGFlinked inhibitor ERRFI1), proteins involved in cell membrane repair (DYSF) or in tissue development (NOG) and two transcription factors (HIF1A and JUN). A group of DEGs is related to the production of cytokines, suggesting their possible role in immunity. Other processes that are significantly associated with the target genes are "regulation of cell death" and "positive regulation of the mitotic cell cycle", suggesting their involvement in the recovery of epithelial tissue. 


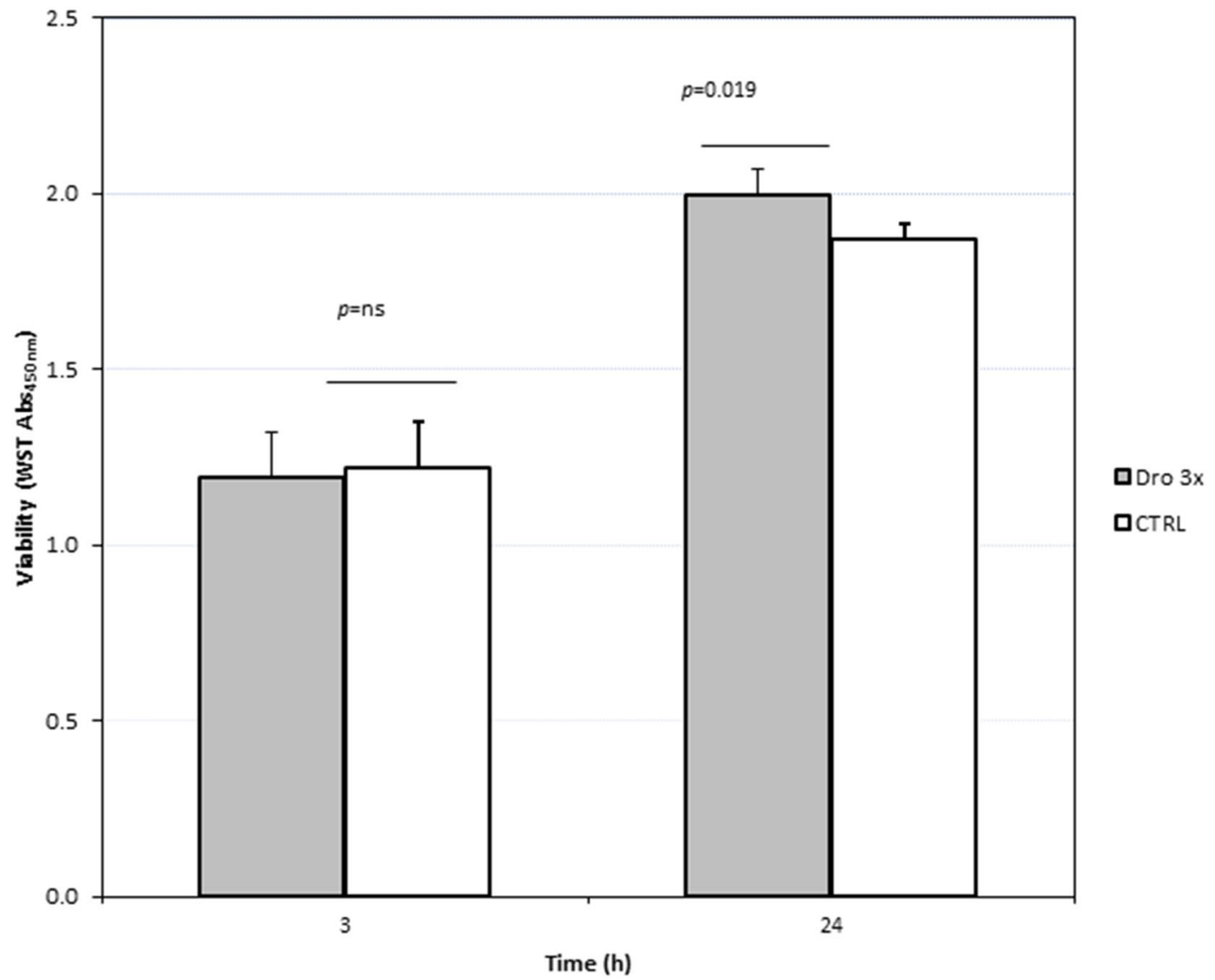

Figure 1. Viability of $16 \mathrm{HBE}$ cells incubated with D. rotundifolia $3 \times$ or Ctrl for $3 \mathrm{~h}$ or $24 \mathrm{~h}$. The colorimetric assay was based on the reduction of the WST reagent as described in the "Materials and method" section.

RT-qPCR validation of the $D$. rotundifolia $3 \times$ target genes. For mRNA expression validation, genes that are associated with enriched biological processes and identified by RNA-seq were investigated by RT-qPCR to validate the effects of $D$. rotundifolia $3 \times$ on mRNA expression (Table 4). Importantly, genes were selected mainly if they were associated with a biological function (Table 3), and then cut-off values were applied to the genes reported in Tables 1 and 2 as follows: log2FoldChange $>0.1$ and $<-0.1$, baseMean $>100$ and transcripts per million (TPM) $>1$ (data not shown). For many candidate genes, the analysis of their expression based on the experimental series of the RNA-seq study was corroborated by the inclusion of results from 4 new follow-up experiments (for a total of 8 independent samples).

As shown in Table 4, RT-qPCR confirmed the significant changes in the regulation of 10 genes identified by the RNA-seq analysis. The remaining investigated genes showed changes similar to those revealed by RNAseq (see Tables 1, 2), which were not statistically significant. Notably, the differential expression changes in the relevant genes associated with the enriched biological processes, such as CY1B1, EREG, AREG, CTGF, and ERR1F1, were verified by RT-qPCR in new follow-up experiments performed with cells treated for $3 \mathrm{~h}$ with $D$. rotundifolia $3 \times$.

Time course of the $D$. rotundifolia $3 \times$ effect. Some representative and very well-expressed genes were selected to investigate the kinetics of the effects of $D$. rotundifolia $3 \times$ during the time course of the cell treatment. A new series of four experiments was performed, in which the cells were incubated for $2 \mathrm{~h}, 6 \mathrm{~h}$, and $24 \mathrm{~h}$ with the medicine or the control. Figure 2 displays the mRNA expression of AREG, CTGF, CXCL8, CYP1B1, EGR1, EREG, IL-1 $\alpha$ and TIPARP in cells with and without $D$. rotundifolia $3 \times$ at the indicated times. The results of all four experiments are separately shown since one of the experiments resulted in higher levels of mRNA expression for a few genes (e.g., CXCL8, EREG and $I L-1 \alpha$ ). Despite the heterogeneity in the basal gene expression, the direction of the effect is clear-cut, and it is largely significant for at least one time point based on the statistics for the paired data. The experiments showed that the effect of $D$. rotundifolia $3 \times$ on most genes starts already at two hours, it is expressed in a higher degree after $6 \mathrm{~h}$, while it decreases at $24 \mathrm{~h}$. Exceptions to this trend are CYP1B1 and TIPARP, which showed the maximum activity at $2 \mathrm{~h}$, which was decreased at $6 \mathrm{~h}$ and further decreased at $24 \mathrm{~h}$.

Based on these results, a new RNA-seq analysis of the samples incubated for $6 \mathrm{~h}$ with D. rotundifolia $3 \times$ was performed to describe in detail and under the best conditions all of the effects of the plant on the gene transcription of bronchial cells. 


\begin{tabular}{|c|c|c|c|c|c|c|}
\hline ENSEMBL ID & Symbol & log2 Fold change & IfcSE & baseMean & padj & Gene description \\
\hline ENSG00000138061 & CYP1B1 & 0.702 & 0.036 & $18,306.85$ & $2.5 \mathrm{E}-79$ & $\begin{array}{l}\text { Cytochrome P450 family } 1 \text { subfamily B } \\
\text { member } 1\end{array}$ \\
\hline ENSG00000163659 & TIPARP & 0.607 & 0.062 & 3055.70 & $7.7 \mathrm{E}-19$ & $\begin{array}{l}\text { TCDD inducible poly(ADP-ribose) poly- } \\
\text { merase }\end{array}$ \\
\hline ENSG00000124882 & EREG & 0.437 & 0.069 & 3248.29 & $1.5 \mathrm{E}-07$ & Epiregulin \\
\hline ENSG00000115008 & IL1A & 0.436 & 0.060 & 3083.65 & $1.4 \mathrm{E}-09$ & Interleukin 1 alpha \\
\hline ENSG00000197632 & SERPINB2 & 0.413 & 0.062 & 2963.76 & $4.0 \mathrm{E}-08$ & Serpin family B member 2 \\
\hline ENSG00000260261 & AC124944.3 & 0.391 & 0.063 & 424.71 & $2.9 \mathrm{E}-07$ & $\begin{array}{l}\text { Programmed cell death } 6 \text { (PDCD6) pseudo- } \\
\text { gene }\end{array}$ \\
\hline ENSG00000118564 & FBXL5 & 0.365 & 0.064 & 1637.91 & $1.3 \mathrm{E}-05$ & F-box and leucine rich repeat protein 5 \\
\hline ENSG00000109321 & AREG & 0.340 & 0.059 & 5103.51 & $6.4 \mathrm{E}-06$ & Amphiregulin \\
\hline ENSG00000182585 & $E P G N$ & 0.335 & 0.064 & 1402.14 & $1.0 \mathrm{E}-04$ & Epithelial mitogen \\
\hline ENSG00000139289 & PHLDA1 & 0.311 & 0.054 & 3077.59 & $7.9 \mathrm{E}-06$ & $\begin{array}{l}\text { Pleckstrin homology like domain family A } \\
\text { member } 1\end{array}$ \\
\hline ENSG00000235220 & $H L A-F$ & 0.306 & 0.062 & 315.13 & $4.2 \mathrm{E}-04$ & Major histocompatibility complex, class I, F \\
\hline ENSG00000104361 & NIPAL2 & 0.287 & 0.063 & 662.15 & $1.8 \mathrm{E}-03$ & NIPA like domain containing 2 \\
\hline ENSG00000119927 & $G P A M$ & 0.277 & 0.070 & 1520.61 & $2.1 \mathrm{E}-02$ & $\begin{array}{l}\text { Glycerol-3-phosphate acyltransferase, mito- } \\
\text { chondrial }\end{array}$ \\
\hline ENSG00000081041 & CXCL2 & 0.273 & 0.070 & 525.50 & $2.8 \mathrm{E}-02$ & C-X-C motif chemokine ligand 2 \\
\hline ENSG00000277758 & FO681492.1 & 0.266 & 0.051 & 96.38 & $3.2 \mathrm{E}-05$ & Synaptotagmin-15 \\
\hline ENSG00000175414 & ARL10 & 0.258 & 0.063 & 339.66 & $9.1 \mathrm{E}-03$ & ADP ribosylation factor like GTPase 10 \\
\hline ENSG00000120738 & EGR1 & 0.256 & 0.046 & 3828.16 & $2.5 \mathrm{E}-05$ & Early growth response 1 \\
\hline ENSG00000154639 & CXADR & 0.254 & 0.062 & 1339.05 & $1.4 \mathrm{E}-02$ & CXADR Ig-like cell adhesion molecule \\
\hline ENSG00000087074 & PPP1R15A & 0.252 & 0.047 & 3208.72 & $7.8 \mathrm{E}-05$ & Protein phosphatase 1 regulatory subunit $15 \mathrm{~A}$ \\
\hline ENSG00000178295 & GEN1 & 0.248 & 0.054 & 1919.26 & $2.4 \mathrm{E}-03$ & GEN1 Holliday junction 5 ' flap endonuclease \\
\hline ENSG00000139292 & LGR5 & 0.247 & 0.054 & 102.30 & $1.8 \mathrm{E}-03$ & $\begin{array}{l}\text { Leucine rich repeat containing G protein- } \\
\text { coupled receptor } 5\end{array}$ \\
\hline ENSG00000136244 & IL6 & 0.244 & 0.066 & 1010.05 & $5.0 \mathrm{E}-02$ & Interleukin 6 \\
\hline ENSG00000005243 & COPZ2 & 0.243 & 0.063 & 159.54 & $2.3 \mathrm{E}-02$ & COPI coat complex subunit zeta 2 \\
\hline ENSG00000235030 & IER3 & 0.233 & 0.049 & 3086.81 & $1.1 \mathrm{E}-03$ & Immediate early response 3 \\
\hline ENSG00000111912 & NCOA7 & 0.230 & 0.043 & 7681.40 & $8.6 \mathrm{E}-05$ & Nuclear receptor coactivator 7 \\
\hline ENSG00000118523 & CTGF & 0.229 & 0.060 & 1498.96 & $3.9 \mathrm{E}-02$ & Cellular communication network factor 2 \\
\hline ENSG00000103995 & CEP152 & 0.225 & 0.062 & 622.41 & $2.9 \mathrm{E}-02$ & Centrosomal protein 152 \\
\hline ENSG00000159086 & PAXBP1 & 0.221 & 0.057 & 1656.63 & $2.9 \mathrm{E}-02$ & PAX3 and PAX7 binding protein 1 \\
\hline ENSG00000102804 & TSC22D1 & 0.212 & 0.048 & 2739.98 & $4.5 \mathrm{E}-03$ & TSC22 domain family member 1 \\
\hline ENSG00000108669 & CYTH1 & 0.212 & 0.057 & 1860.07 & $5.0 \mathrm{E}-02$ & Cytohesin 1 \\
\hline ENSG00000134294 & SLC38A2 & 0.208 & 0.032 & $11,532.92$ & $1.0 \mathrm{E}-07$ & Solute carrier family 38 member 2 \\
\hline ENSG00000103257 & SLC7A5 & 0.194 & 0.030 & $35,338.50$ & $1.4 \mathrm{E}-07$ & Solute carrier family 7 member 5 \\
\hline ENSG00000129474 & AJUBA & 0.181 & 0.042 & 5412.41 & $6.6 \mathrm{E}-03$ & Ajuba LIM protein \\
\hline ENSG00000100644 & HIFIA & 0.180 & 0.045 & 6302.38 & $1.8 \mathrm{E}-02$ & Hypoxia inducible factor 1 subunit alpha \\
\hline ENSG00000138434 & ITPRID2 & 0.152 & 0.039 & $18,731.03$ & $3.4 \mathrm{E}-02$ & ITPR interacting domain containing 2 \\
\hline ENSG00000010310 & GIPR & 0.151 & 0.036 & 120.73 & $2.5 \mathrm{E}-03$ & Gastric inhibitory polypeptide receptor \\
\hline ENSG00000128272 & ATF4 & 0.146 & 0.037 & $12,347.69$ & $2.4 \mathrm{E}-02$ & Activating transcription factor 4 \\
\hline ENSG00000023445 & BIRC3 & 0.137 & 0.037 & $13,084.30$ & $5.0 \mathrm{E}-02$ & Baculoviral IAP repeat containing 3 \\
\hline ENSG00000206489 & PPP1R10 & 0.106 & 0.026 & 26.98 & $1.0 \mathrm{E}-07$ & Protein phosphatase 1 regulatory subunit 10 \\
\hline ENSG00000278516 & LENG1 & 0.050 & 0.018 & 12.47 & $9.7 \mathrm{E}-04$ & Leukocyte receptor cluster member 1 \\
\hline ENSG00000061455 & PRDM6 & 0.032 & 0.019 & 21.63 & $1.4 \mathrm{E}-02$ & PR/SET domain 6 \\
\hline ENSG00000173503 & LTA & 0.028 & 0.016 & 15.34 & $2.9 \mathrm{E}-02$ & Lymphotoxin alpha \\
\hline ENSG00000189068 & VSTM1 & 0.027 & 0.016 & 24.23 & $6.6 \mathrm{E}-03$ & $\begin{array}{l}\text { V-set and transmembrane domain containing } \\
1\end{array}$ \\
\hline ENSG00000275428 & AC024940.6 & 0.026 & 0.016 & 23.11 & $3.3 \mathrm{E}-03$ & Ovostatin 2 \\
\hline
\end{tabular}

Table 1. Statistically significant upregulated genes in $16 \mathrm{HBE}$ cells treated for $3 \mathrm{~h}$ with $D$. rotundifolia $3 \mathrm{x}$. The table reports the gene identification (ENSEMBL ID, gene symbol and description), the degree of the average expression changes for the 4 experiments (log2FoldChange), the standard error of the change (lfcSE), the mean expression value expressed as the normalized read counts (baseMean) and the adjusted p-values (padj) corrected by the Benjamini-Hochberg (BH) method. 


\begin{tabular}{|c|c|c|c|c|c|c|}
\hline ENSEMBL ID & Symbol & log2FoldChange & IfcSE & baseMean & padj & Gene description \\
\hline ENSG00000059804 & $S L C 2 A 3$ & -0.510 & 0.070 & 2797.19 & $1.4 \mathrm{E}-09$ & Solute carrier family 2 member 3 \\
\hline ENSG00000165507 & DEPP1 & -0.482 & 0.070 & 807.55 & $2.1 \mathrm{E}-08$ & DEPP1 autophagy regulator \\
\hline ENSG00000116285 & ERRFI1 & -0.384 & 0.064 & 5529.11 & $2.5 \mathrm{E}-06$ & ERBB receptor feedback inhibitor 1 \\
\hline ENSG00000168209 & DDIT4 & -0.323 & 0.065 & 4188.35 & $3.7 \mathrm{E}-04$ & DNA damage inducible transcript 4 \\
\hline ENSG00000146830 & GIGYF1 & -0.322 & 0.068 & 2461.89 & $1.2 \mathrm{E}-03$ & GRB10 interacting GYF protein 1 \\
\hline ENSG00000183691 & NOG & -0.303 & 0.070 & 430.04 & $5.2 \mathrm{E}-03$ & Noggin \\
\hline ENSG00000204267 & TAP2 & -0.297 & 0.070 & 824.16 & $9.1 \mathrm{E}-03$ & $\begin{array}{l}\text { Transporter 2, ATP binding cassette subfamily } \\
\text { B member }\end{array}$ \\
\hline ENSG00000213859 & KCTD11 & -0.284 & 0.063 & 1506.09 & $2.8 \mathrm{E}-03$ & $\begin{array}{l}\text { Potassium channel tetramerization domain } \\
\text { containing } 11\end{array}$ \\
\hline ENSG00000169992 & NLGN2 & -0.273 & 0.068 & 1214.66 & $1.6 \mathrm{E}-02$ & Neuroligin 2 \\
\hline ENSG00000171345 & KRT19 & -0.269 & 0.050 & $30,099.26$ & $8.1 \mathrm{E}-05$ & Keratin 19 \\
\hline ENSG00000148926 & $A D M$ & -0.266 & 0.070 & 392.45 & $3.9 \mathrm{E}-02$ & Adrenomedullin \\
\hline ENSG00000177606 & $J U N$ & -0.260 & 0.062 & 1999.96 & $9.1 \mathrm{E}-03$ & $\begin{array}{l}\text { Jun proto-oncogene, AP-1 transcription factor } \\
\text { subunit }\end{array}$ \\
\hline ENSG00000145331 & TRMT10A & -0.259 & 0.068 & 387.61 & $3.8 \mathrm{E}-02$ & tRNA methyltransferase $10 \mathrm{~A}$ \\
\hline ENSG00000135636 & DYSF & -0.253 & 0.056 & 2045.20 & $2.7 \mathrm{E}-03$ & Dysferlin \\
\hline ENSG00000099308 & MAST3 & -0.253 & 0.066 & 455.28 & $2.9 \mathrm{E}-02$ & $\begin{array}{l}\text { Microtubule associated serine/threonine kinase } \\
3\end{array}$ \\
\hline ENSG00000113369 & ARRDC3 & -0.244 & 0.059 & 942.12 & $1.4 \mathrm{E}-02$ & Arrestin domain containing 3 \\
\hline ENSG00000104517 & UBR5 & -0.235 & 0.056 & 3357.96 & $1.0 \mathrm{E}-02$ & $\begin{array}{l}\text { Ubiquitin protein ligase E3 component } \\
\text { n-recognin } 5\end{array}$ \\
\hline ENSG00000186352 & ANKRD37 & -0.222 & 0.049 & 73.34 & $1.2 \mathrm{E}-03$ & Ankyrin repeat domain 37 \\
\hline ENSG00000146674 & IGFBP3 & -0.204 & 0.053 & $22,877.33$ & $3.3 \mathrm{E}-02$ & Insulin like growth factor binding protein 3 \\
\hline ENSG00000115524 & $S F 3 B 1$ & -0.203 & 0.039 & $11,529.03$ & $1.2 \mathrm{E}-04$ & Splicing factor $3 \mathrm{~b}$ subunit 1 \\
\hline ENSG00000070614 & NDST1 & -0.175 & 0.036 & $13,053.04$ & $1.0 \mathrm{E}-03$ & $\mathrm{~N}$-deacetylase and $\mathrm{N}$-sulfotransferase 1 \\
\hline ENSG00000232070 & TMEM253 & -0.113 & 0.028 & 38.83 & $1.4 \mathrm{E}-05$ & Transmembrane protein 253 \\
\hline ENSG00000241370 & RPP21 & -0.056 & 0.019 & 14.73 & $5.3 \mathrm{E}-04$ & Ribonuclease P/MRP subunit p21 \\
\hline ENSG00000282752 & CTDP1 & -0.040 & 0.018 & 14.79 & $3.9 \mathrm{E}-02$ & CTD phosphatase subunit 1 \\
\hline ENSG00000069188 & SDK2 & -0.029 & 0.013 & 8.71 & $1.2 \mathrm{E}-02$ & Sidekick cell adhesion molecule 2 \\
\hline
\end{tabular}

Table 2. Statistically significant downregulated genes in $16 \mathrm{HBE}$ cells treated for $3 \mathrm{~h}$ with $D$. rotundifolia $3 \mathrm{x}$. For the legend see Table 1.

RNA sequencing of $16 \mathrm{HBE}$ cells treated with $D$. rotundifolia $3 \times$ for $6 \mathrm{~h}$. RNA-seq was performed using the same parameters used for the RNA-seq of $16 \mathrm{HBE}$ cells treated with D. rotundifolia $3 \times$ for $3 \mathrm{~h}$ as well as the bioinformatics analysis. All samples passed the quality control tests as described for the RNA-seq of the 3 h-treated samples.

The DESeq2 output generated a list of 495 DEGs in 16HBE cells after $6 \mathrm{~h}$ of treatment with $D$. rotundifolia $3 \times$ compared to treatment with the control (padj <0.05), which contains a majority of upregulated genes $(n=334)$. Figure 3 depicts the DEGs in a Volcano plot, which highlights (blue dots) all the genes $(\mathrm{n}=117)$ that had a statistically significant change (adjusted $p$-value $<0.05$ ) and a log2FoldChange higher than +0.4 or less than -0.4 . For this analysis, a log2FoldChange cut-off value was used since the number of DEGs was much higher compared to that identified by the RNA-seq performed for the $3 \mathrm{~h}$ treatment. Figure 3 shows that after $6 \mathrm{~h}$ of incubation, there were a high number of DEGs, especially upregulated genes, which is in accordance with what is shown in Fig. 2. From a qualitative point of view, a similarity is observed in the genes whose expression is increased at the two different incubation times. Such a similarity is reflected by the upregulation of some genes, such as CYP1B1, EPGN, EREG, SERPINB2, IL-1 $\alpha$, AREG, and PHDLA1, which were also upregulated by cells treated with $D$. rotundifolia $3 \times$ for $3 \mathrm{~h}$ (see Table 1 ). Regarding the downregulated genes (left side of Fig. 3 ), some new genes associated with an inhibitory effect are highlighted, including IGFBP3, PLAC8, MAN2B2, and BNIP3, which, except for IGFBP3, were identified only after $6 \mathrm{~h}$ of incubation and not after a shorter exposure $(2 \mathrm{or} 3 \mathrm{~h})$. Moreover, genes that were slightly downregulated after $3 \mathrm{~h}$ of $D$. rotundifolia $3 \times$ treatment, such as ERRFI1, were not found to be regulated after $6 \mathrm{~h}$ of treatment.

Functional analysis. The 117 differentially expressed genes were ranked by the adjusted p-value significance, and GO enrichment analysis was performed using gprofiler2 as described in the "Materials and methods" section. The enrichment results for the $6 \mathrm{~h}$ data set (Fig. 4) show a wide range of information concerning the biological processes (blue bars in Fig. 4) and molecular functions (red bars). Similar enriched biological processes were observed after $6 \mathrm{~h}$ and $3 \mathrm{~h}$ of $D$. rotundifolia $3 \times$ treatment, such as functions related to blood vessel development, regulation of epithelial cell proliferation and cytokine production. Moreover, there was an increase in biological processes related to inflammation and chemotaxis after $6 \mathrm{~h}$ of $D$. rotundifolia $3 \times$ treatment due to the 


\begin{tabular}{|l|l|l|l|l|}
\hline GO term & Biological processes & $p$-value & n. genes & DEGs \\
\hline GO:0010575 & Positive regulation of vascular endothelial growth factor production & $8.24 \mathrm{E}-05$ & 5 & CYP1B1, IL1A, HIF1A, ATF4, IL6 \\
\hline GO:0048583 & Regulation of response to stimulus & 0.003206 & 34 & $\begin{array}{l}\text { CYP1B1, IL1A, SERPINB2, PPP1R10, EREG, ERRFI1, AREG, EGR1, } \\
\text { PPP1R15A, NCOA7, EPGN, DDIT4, HLA-F, IER3, LGR5, GIPR, } \\
\text { HYSF, NOG, AJUBA, JUN, UBR5, ARRDC3, CXADR, NLGN2, } \\
\text { ILF1A, GPAM, ATF4, LTA, IGFBP3, CTDP1, ADM, BIRC3, CYTH1, }\end{array}$ \\
\hline GO:0050673 & Epithelial cell proliferation & 0.003256 & 10 & $\begin{array}{l}\text { EREG, ERRFI1, AREG, EPGN, LGR5, DYSF, NOG, JUN, HIF1A, } \\
\text { IGFBP3 }\end{array}$ \\
\hline GO:0042035 & Regulation of cytokine biosynthetic process & 0.005926 & 4 & IL1A, EREG, ERRFI1, EGR1 \\
\hline GO:1901184 & Regulation of ERBB signalling pathway & 0.008551 & 4 & EREG, ERRFI1, AREG, EPGN \\
\hline GO:0001944 & Vasculature development & 0.011299 & 13 & $\begin{array}{l}\text { CYP1B1, TIPARP, IL1A, EREG, ERRFI1, EGR1, EPGN, DYSF, NOG, } \\
\text { JUN, HIF1A, ADM, IL6 }\end{array}$ \\
\hline GO:0001819 & Positive regulation of cytokine production & 0.014852 & 10 & CYP1B1, IL1A, EREG, EGR1, HLA-F, HIF1A, ATF4, LTA, BIRC3, IL6 \\
\hline GO:0045931 & Positive regulation of mitotic cell cycle & 0.017961 & 5 & IL1A, PPP1R10, EREG, EPGN, GEN1 \\
\hline GO:0050678 & Regulation of epithelial cell proliferation & 0.02095 & 8 & EREG, ERRFI1, AREG, EPGN, DYSF, NOG, JUN, HIF1A \\
\hline GO:0010941 & Regulation of cell death & 0.021917 & 19 & $\begin{array}{l}\text { CYP1B1, IL1A, SERPINB2, PPP1R10, PHLDA1, EGR1, NCOA7, } \\
\text { ADIT4, HLA-F, IER3, NOG, JUN, HIF1A, ATF4, LTA, IGFBP3, }\end{array}$ \\
\hline GO:0001568 & Blood vessel development & 0.038694 & 12 & $\begin{array}{l}\text { CYP1B1, TIPARP, IL1A, EREG, EGR1, EPGN, DYSF, NOG, JUN, } \\
\text { HIF1A, ADM, IL6 }\end{array}$ \\
\hline GO:0050679 & Positive regulation of epithelial cell proliferation & 0.049145 & 6 & AREG, EPGN, DYSF, NOG, JUN, HIF1A \\
\hline
\end{tabular}

Table 3. Representative biological processes and associated differentially expressed genes (DEGs) in $16 \mathrm{HBE}$ cells treated with $D$. rotundifolia $3 \times$ for $3 \mathrm{~h}$. Table reports enriched biological processes identification (GO term and Biological process name), the number of differentially expressed genes belonging to each biological processes and their gene symbols. $p$-values indicate the enrichment significance obtained with g_SCS algorithm of gprofiler2 analysis, as described in the "Materials and methods" section.

upregulation of additional cytokines and chemokines. These data confirm that there is an increase in the effects and suggest new functions associated with $D$. rotundifolia $3 \times$ treatment of $16 \mathrm{HBE}$ cells after $6 \mathrm{~h}$.

To draw a functional picture of the enriched functions and their correlations, a network that associates the genes with the functions in the biological model of bronchial epithelial cells was constructed (Fig. 5). Functions are representative and were chosen based on our experimental model and enrichment p-value. The Log2FoldChange values from the DESeq2 output are depicted by the coloured nodes, which shows that the enrichment of these biological functions is mostly associated with the upregulated genes. This was expected since the number of upregulated genes observed after $D$. rotundifolia $3 \times$ treatment was almost 3 times higher than the number of downregulated genes. Moreover, genes that were upregulated by $D$. rotundifolia $3 \times$ are associated with many biological processes, while this was not the case for the downregulated genes.

\section{Discussion}

In this study, functional genomic research was performed to explore the effects of a medicinal plant traditionally used for respiratory diseases on its potential target cells in vitro, i.e., bronchial epithelial cells. This study shows that a diluted herbal extract used in a traditional homeopathic pharmacopoeia ${ }^{5,9-12}$ can induce a change in mRNA expression that can be measured reliably and reproducibly. Low doses of traditional plants and homeopathic dilutions are now being investigated by means of molecular biology techniques for differential gene expression analysis and bioinformatics ${ }^{24-28}$.

Screening in bronchial cells with RNA-seq analysis showed that low amounts of $D$. rotundifolia at a $3 \times$ dilution, which represents a dose commonly used in homeopathic and phytotherapeutic syrups, changed the expression of dozens of genes after $3 \mathrm{~h}$, and this effect was amplified after $6 \mathrm{~h}$ of treatment. Validation with RT-qPCR confirmed the differential expression of the genes of interest and showed that after $6 \mathrm{~h}$ of $D$. rotundifolia $3 \times$ treatment, there was an increase in mRNA expression. Since RT-qPCR sensitivity is higher than that of RNA-seq, such results support the findings of the RNA-seq analysis, suggesting that treatment with $D$. rotundifolia $\times$ can be followed-up by the investigation of the expression of these genes.

In our experiments, $D$. rotundifolia $3 \times$ did not impair cell viability or adherence, suggesting that this dilution is safe when tested directly in cell culture. The same dilution exerted a stimulatory effect on the expression of several genes, including those of inflammatory cytokines. Furthermore, the transcriptomic analysis and RT-qPCR confirmation suggest that, at the dilution used, D. rotundifolia $3 \times$ works mainly as a stimulant and not as an inhibitor of cell functions. This result is different from the data reported by others in HMC-1 human mast cells ${ }^{29}$, suggesting the anti-inflammatory effects of the plant. This apparent discrepancy could be due to the difference in the biological model, since mast cells are typical inflammatory cells and were stimulated before treatment with $D$. rotundifolia, while our epithelial cells were treated without previous inflammatory stimuli. However, even more importantly, different doses may be utilized: Fukushima et al. ${ }^{29}$ obtained an inhibitory effect by using nondiluted fractions of the whole extract of $D$. rotundifolia, while in the present study, the cells were treated with a $3 \times$ dilution (1000 times) of the ethanolic extract. 


\begin{tabular}{|c|c|c|c|c|c|c|}
\hline Gene & $\mathbf{n}$ & D. rotundifolia $3 \mathrm{x}(\mathrm{MNE})($ mean $\pm \mathrm{SD})$ & Ctrl $(\mathrm{MNE})($ mean \pm SD $)$ & Log2FoldChange & SE & $p$-val \\
\hline TIPARP & 4 & $0.0082 \pm 0.0008$ & $0.0041 \pm 0.0003$ & 0.982 & 0.149 & 0.013 \\
\hline CYP1B1 & 8 & $0.0549 \pm 0.0044$ & $0.0345 \pm \mathrm{s} 0.0042$ & 0.921 & 0.069 & 0.000 \\
\hline SERPINB2 & 4 & $0.0004 \pm 0.0000$ & $0.0002 \pm 0.0000$ & 0.781 & 0.129 & 0.026 \\
\hline EREG & 8 & $0.0104 \pm 0.0025$ & $0.0084 \pm 0.0031$ & 0.574 & 0.099 & 0.037 \\
\hline AREG & 8 & $0.0492 \pm 0.0109$ & $0.0398 \pm 0.0115$ & 0.519 & 0.225 & 0.018 \\
\hline EPGN & 8 & $0.0190 \pm 0.0041$ & $0.0138 \pm 0.0036$ & 0.491 & 0.157 & 0.094 \\
\hline$I L 1 A$ & 8 & $0.0121 \pm 0.0014$ & $0.0088 \pm 0.0006$ & 0.433 & 0.077 & 0.337 \\
\hline CTGF & 4 & $0.0090 \pm 0.0006$ & $0.0068 \pm 0.0005$ & 0.415 & 0.121 & 0.045 \\
\hline PPP1R15A & 4 & $0.0132 \pm 0.0015$ & $0.0101 \pm 0.0009$ & 0.381 & 0.162 & 0.102 \\
\hline CXCL2 & 4 & $0.0279 \pm 0.0041$ & $0.0214 \pm 0.0027$ & 0.362 & 0.16 & 0.138 \\
\hline$A J U B A$ & 4 & $0.0187 \pm 0.0019$ & $0.0146 \pm 0.0006$ & 0.34 & 0.142 & 0.125 \\
\hline PHLDA1 & 8 & $0.0255 \pm 0.0071$ & $0.0205 \pm 0.0056$ & 0.331 & 0.188 & 0.034 \\
\hline IL6 & 4 & $0.0110 \pm 0.0010$ & $0.0088 \pm 0.0003$ & 0.305 & 0.092 & 0.067 \\
\hline EGR1 & 8 & $0.0566 \pm 0.0090$ & $0.0472 \pm 0.0053$ & 0.239 & 0.174 & 0.115 \\
\hline CXCL8 & 4 & $0.0112 \pm 0.0007$ & $0.0097 \pm 0.0007$ & 0.222 & 0.101 & 0.136 \\
\hline NCOA7 & 4 & $0.0034 \pm 0.0004$ & $0.0030 \pm 0.0002$ & 0.177 & 0.161 & 0.342 \\
\hline SASH1 & 4 & $0.0029 \pm 0.0003$ & $0.0026 \pm 0.0003$ & 0.17 & 0.204 & 0.446 \\
\hline HBEGF & 4 & $0.0030 \pm 0.0004$ & $0.0027 \pm 0.0001$ & 0.106 & 0.095 & 0.339 \\
\hline DDIT3 & 4 & $0.0077 \pm 0.0004$ & $0.0076 \pm 0.0008$ & 0.03 & 0.128 & 0.923 \\
\hline PIK3C2A & 4 & $0.0030 \pm 0.0003$ & $0.0029 \pm 0.0002$ & 0.028 & 0.179 & 0.801 \\
\hline$N R 2 F 2$ & 4 & $0.0482 \pm 0.0024$ & $0.0504 \pm 0.0067$ & -0.035 & 0.144 & 0.700 \\
\hline$I G F B P 3$ & 4 & $0.2175 \pm 0.0381$ & $0.2247 \pm 0.0377$ & -0.039 & 0.138 & 0.758 \\
\hline IRS2 & 4 & $0.0078 \pm 0.0003$ & $0.0086 \pm 0.0008$ & -0.123 & 0.158 & 0.474 \\
\hline$J U N$ & 4 & $0.0047 \pm 0.0006$ & $0.0051 \pm 0.0004$ & -0.14 & 0.075 & 0.200 \\
\hline$A D M$ & 4 & $0.0022 \pm 0.0002$ & $0.0025 \pm 0.0001$ & -0.214 & 0.057 & 0.022 \\
\hline DDIT4 & 8 & $0.0386 \pm 0.0102$ & $0.0514 \pm 0.0160$ & -0.404 & 0.248 & 0.403 \\
\hline$S C L 2 A 3$ & 4 & $0.0093 \pm 0.0010$ & $0.0123 \pm 0.0010$ & -0.407 & 0.176 & 0.115 \\
\hline ERRFII & 8 & $0.0180 \pm 0.0026$ & $0.0234 \pm 0.0019$ & -0.42 & 0.172 & 0.006 \\
\hline$D E P P 1$ & 4 & $0.0058 \pm 0.0004$ & $0.0081 \pm 0.0007$ & -0.478 & 0.149 & 0.059 \\
\hline ARRDC3 & 8 & $0.0040 \pm 0.0009$ & $0.0067 \pm 0.0009$ & -0.757 & 0.11 & 0.017 \\
\hline
\end{tabular}

Table 4. mRNA expression in $16 \mathrm{HBE}$ cells incubated with $D$. rotundifolia $3 \times$ or Ctrl for $3 \mathrm{~h}$. $16 \mathrm{HBE}$ cells were cultured with $D$. rotundifolia $3 \times$ or the control for $3 \mathrm{~h}$, and their mRNA expression of the indicated genes was evaluated by RT-qPCR. Gene expression is depicted as the mean normalized expression (MNE) after GAPDH mRNA normalization (mean \pm SD of the indicated number of experiments). $p$-values were calculated by Student's $t$ test. Values in bold indicate $p$-value $<0.05$.

Paper et al. ${ }^{30}$ reported that extracts of $D$. rotundifolia and other species, tested in hen's egg model, show efficacy as anti-inflammatory, antispasmodic and antiangiogenic agents. In contrast, the data of our study suggest that treatment with $D$. rotundifolia $3 \times$ can trigger a mild inflammatory response in $16 \mathrm{HBE}$ cells. The latter effect can be attributed to the increase in the mRNA expression of pro-inflammatory cytokines such as $I L-1 \alpha, I L-1 \beta$ and $I L-6$ and chemokines such as CXCL1, CXCL2 and CXCL8. Discrepancies in the data from Paper et al..$^{30}$ could be due to the different models or, again, to the doses applied, since we used a homeopathic dilution of the plant extract, which represents a biological stimulus and does not inhibit key cell functions ${ }^{24}$, as conventional antiinflammatory agents do. Moreover, it is well known that a mild inflammatory response could be beneficial to the immune system by increasing the apoptosis and clearance of inflammatory cells ${ }^{31,32}$. This concept is fully in agreement with homeopathic theory and tradition, in which low doses of pathogenic substances and/or minimally stressful stimuli trigger endogenous responses of "vital energy", which eventually lead to healing at the cell, tissue or systemic levels ${ }^{33-35}$. The presence of CXCL1, CXCL2 and CXCL8, which are mostly chemoattractants for neutrophils, suggests that treatment with $D$. rotundifolia $3 \times$ can help to establish a ready-state immune barrier against pathogens in case of bronchial epithelial tissue damage ${ }^{36}$.

Interestingly, $D$. rotundifolia $3 \times$ treatment increased the expression of specific epidermal growth factors, such as $A R E G, E R E G$ and $E P G N$, by $16 \mathrm{HBE}$ cells. The upregulation of these factors suggests that $D$. rotundifolia $3 \times$ plays a positive role in the regulation of cell survival, cell proliferation and wound healing. Moreover, all these factors bind to epidermal growth factor receptor (EGFR) to accomplish their functions. In this context, EGFR is widely expressed on the cells present in the bronchial environment, suggesting that the possible release of these growth factors affects not only the proliferation of bronchial epithelial cells but also that of endothelial cells, fibroblasts and vascular cells. In the case of damage to bronchial epithelial tissue, D. rotundifolia $3 \times$ could contribute to faster healing of the bronchial microenvironment.

$C Y P 1 B 1$ was the most highly expressed gene after treatment with $D$. rotundifolia $3 \times$ at both time points shown in this study. CYP1B1 is probably activated as a response to treatment with D. rotundifolia $3 \mathrm{x}$, since CYP1B1 
AREG
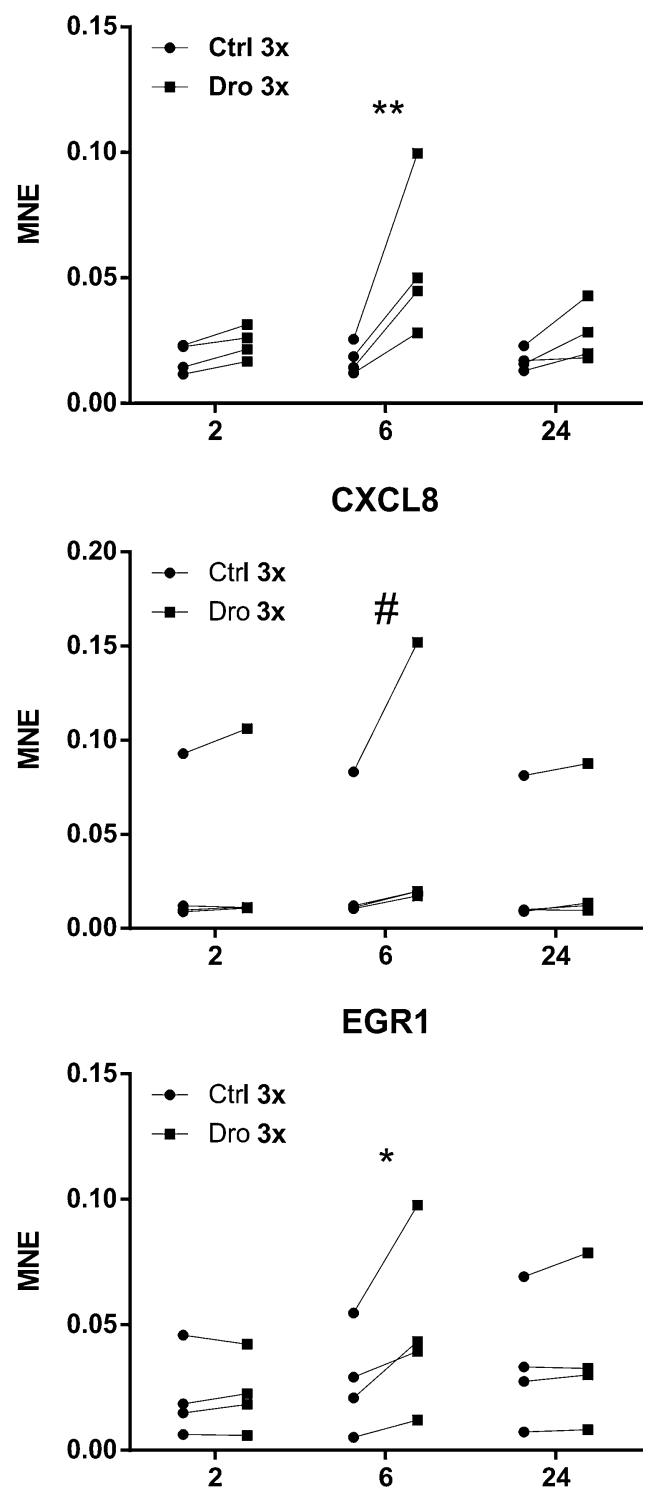

\section{IL-1alpha}

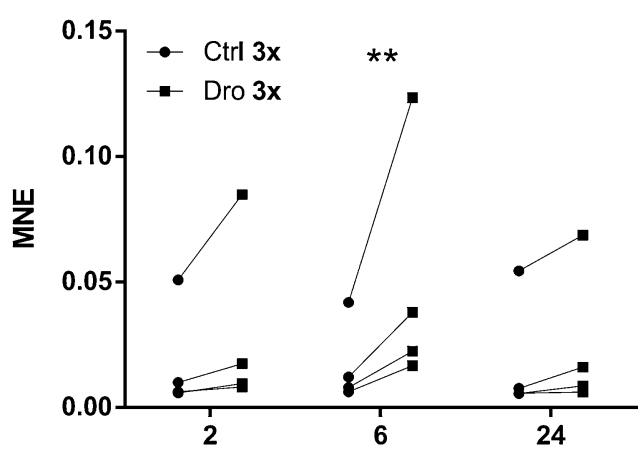

CTGF

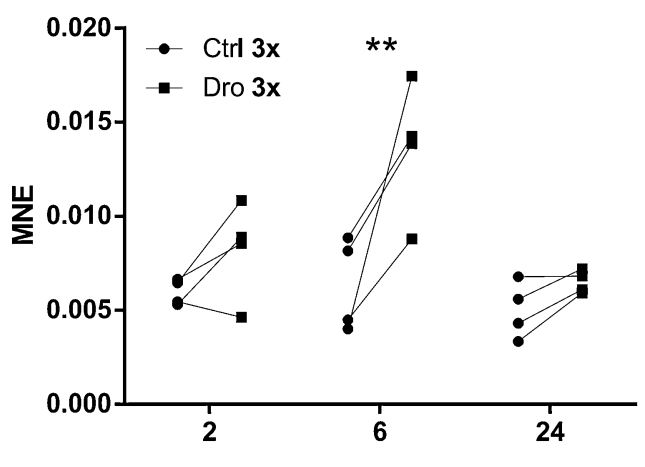

CYP1B1
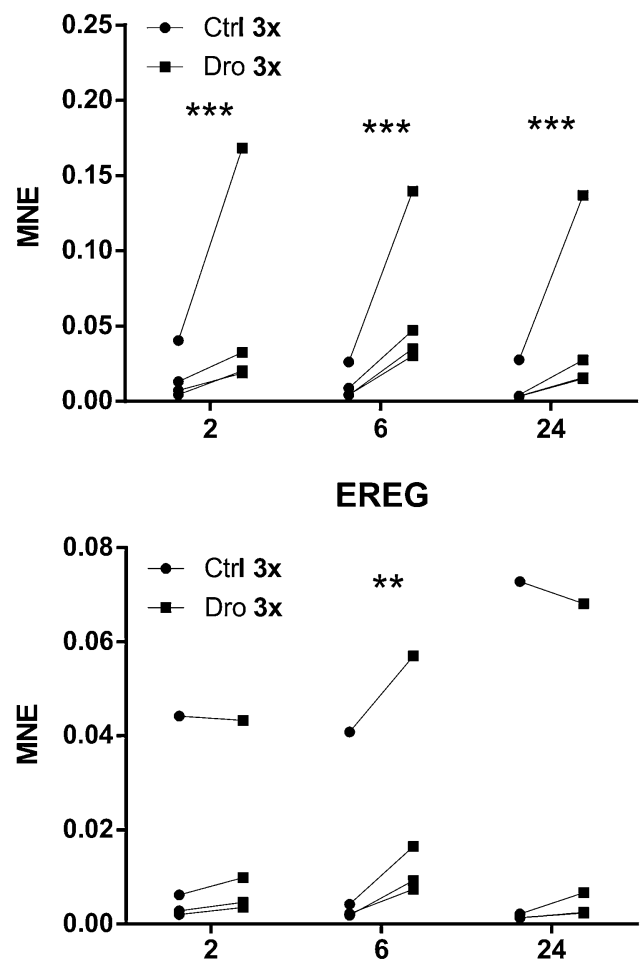

TIPARP

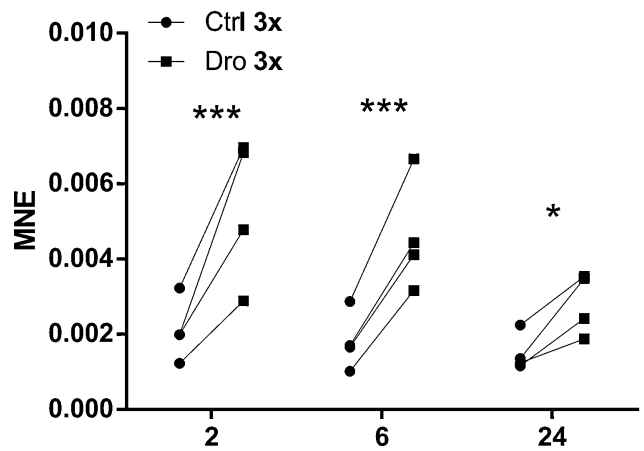

Figure 2. Kinetics of AREG, CTGF, CXCL8, CYP1B1, EGR1, EREG, IL-1 $\alpha$ and TIPARP mRNA expression in $16 \mathrm{HBE}$ cells incubated with $D$. rotundifolia $3 \mathrm{x}$. $16 \mathrm{HBE}$ cells were cultured with $D$. rotundifolia $3 \times($ Dro $3 \times$ ) or Ctrl (Ctrl 3x) for up to $24 \mathrm{~h}$ to evaluate mRNA expression by RT-qPCR. Gene expression is depicted as the mean normalized expression (MNE) after GAPDH mRNA normalization $(\mathrm{n}=4)$. Asterisks indicate a significant increase: ${ }^{*} p<0.05,{ }^{* *} p<0.01,{ }^{* *} p<0.001,{ }^{*} p=0.057$ by two-way ANOVA followed by Bonferroni's post-test. 


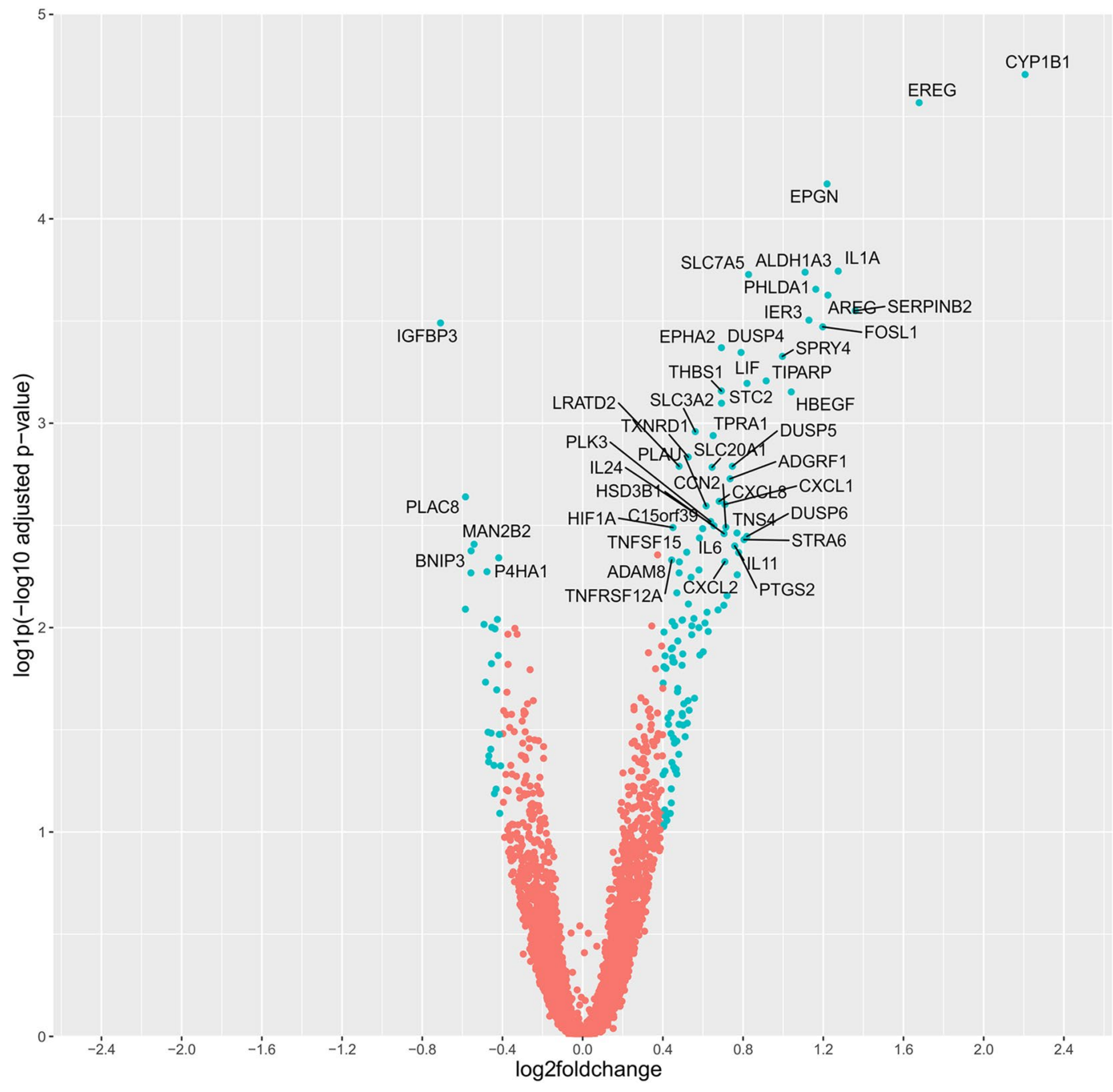

Figure 3. Volcano plot of the differential expression analysis of $16 \mathrm{HBE}$ cells treated with $D$. rotundifolia $3 \times$ for $6 \mathrm{~h}$. The scattered points represent genes: the $\mathrm{x}$-axis is the log2foldchange for the D. rotundifolia $3 \times$-treated $16 \mathrm{HBE}$ cells. The $\mathrm{y}$-axis shows the $\log 1 \mathrm{p}(-\log 10$ adjusted $\mathrm{p}$-value), which better highlights the differentially expressed genes in our experimental conditions. Blue dots represent genes that were significantly differentially expressed (adjusted p-value $<0.05$ ) with a $\log 2$ foldchange $<-0.4$ or $>0.4$ after 6 h treatment with $D$. rotundifolia $3 \times$.

belongs to the cytochrome family and is involved in the metabolism of xenobiotics. Moreover, as shown in Fig. 5, $C Y P 1 B 1$ is connected to the regulation of angiogenesis and the positive regulation of cytokine production because of its role as an antioxidant and NF-kB regulator ${ }^{37,38}$, respectively.

This study has some limitations since some of the findings are based on bioinformatics analysis, and mRNA expression and functional experiments are required to verify the mechanisms of action and effects of the treatment with $D$. rotundifolia $3 \times$. In addition, it is important to observe that after $6 \mathrm{~h}$ of $D$. rotundifolia $3 \times$ treatment, there was a number of differentially expressed genes with $\log 2$ FoldChange values ranging from +0.4 to -0.4 , which were not included in the analysis for this manuscript but could be considered for a future study. Indeed, the effects on gene regulation represent only a first functional step of the action of the plant that we have highlighted, and our hypotheses will have to be confirmed with adequate studies in laboratory animals to investigate the therapeutic potential and the mechanisms of action of this plant.

In conclusion, the data highlight the complex and multifaceted action of the plant on the different layers of the bronchial mucosa, as summarized in Fig. 6. The mRNA expression changes in 16HBE cells treated with $D$. rotundifolia $3 \times$ suggest its direct action on the epithelial cell, which protects its integrity with respect to toxic substances (CYP1B1) and stimulates its reparative capacity (AREG, EREG and EPGN). In addition, epithelial cells transmit molecular signals that activate mild inflammation (pro-inflammatory cytokines) and recruit innate defence- and angiogenesis-associated cells. 


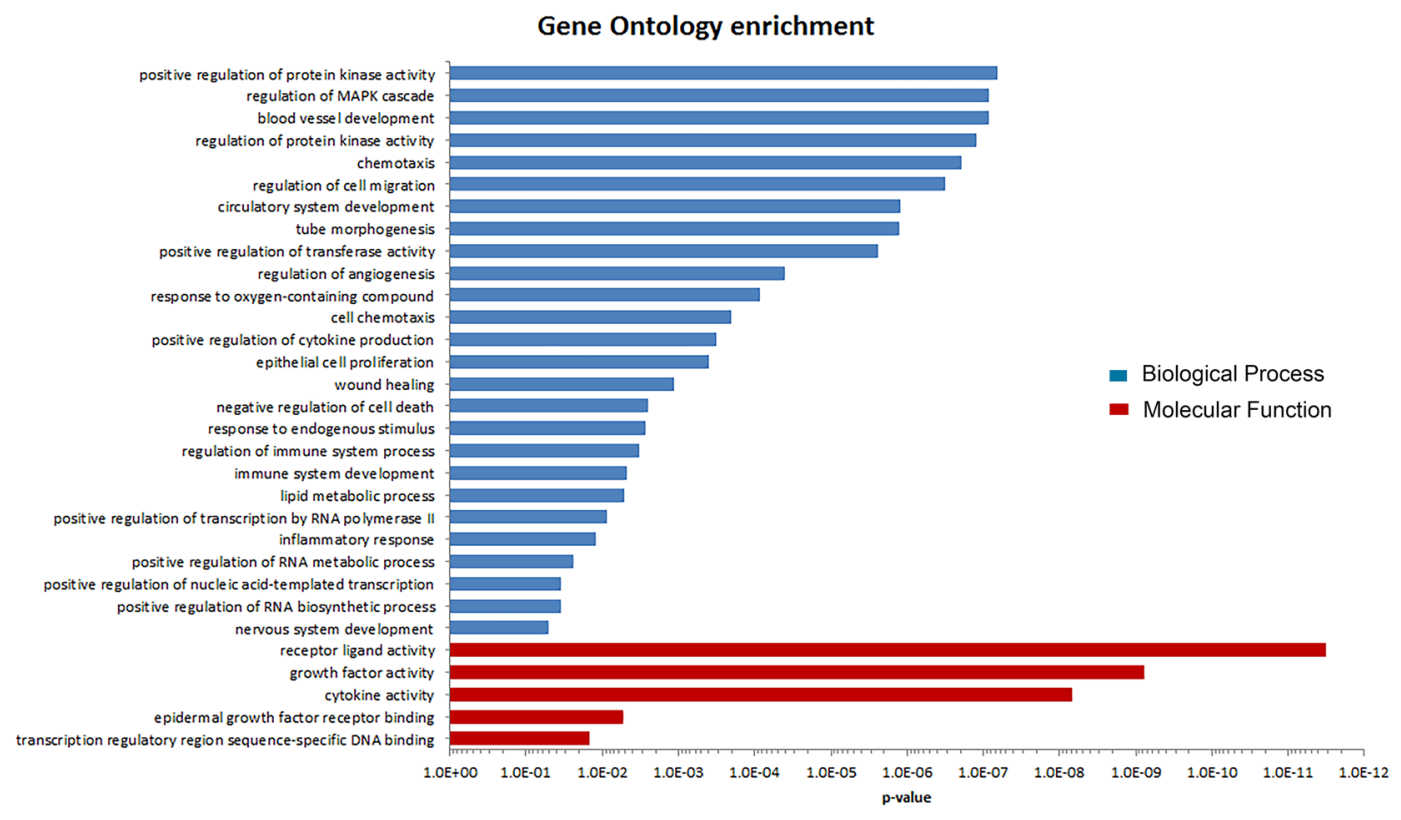

Figure 4. Representative gene ontology classifications of the differentially expressed genes in $16 \mathrm{HBE}$ cells treated with $D$. rotundifolia $3 \times$. The differentially expressed genes were classified into two categories: biological processes and molecular functions. Gene ontology enrichment analysis was performed using the "gost" function from the gprofiler2 package according to the gene list ranked by the adjusted $p$-value. GO terms with p-values $<0.05$ were considered significant.

\begin{abstract}
Materials and methods
Preparation of $\boldsymbol{D}$. rotundifolia samples. The original round leaf sundew plant, identified with the botanical name Drosera rotundifolia, was commercially purchased (Monteagle Herbs, ON, Canada; Document of Authenticity \#42808). To the best of our knowledge, no issues related to the Convention on the Trade in Endangered Species of Wild Fauna and Flora have been raised. Drosera rotundifolia (ethanolic extract) was prepared by Standard Homeopathic Company, CA, USA. The extract contained $1 \mathrm{~g}$ dried whole plant macerated in $10 \mathrm{~mL}$ of $45 \% \mathrm{EtOH}$, which corresponds to D. rotundifolia $1 \times$. Before the experiments, D. rotundifolia $1 \times$ ethanolic extract was serially diluted $1: 10(0.5 \mathrm{~mL}+4.5 \mathrm{~mL})$ twice in sterile pyrogen-free water (B-Braun, Melsungen, Germany) in a 14-mL clean glass tube, which immediately vigorously shaken (succussed) with a Dyna A mechanical shaker that delivered 20 strokes/s for $7.5 \mathrm{~s}$ with an $11-\mathrm{mm}$ travel distance. The final solution corresponds to a $3 \times$ dilution in $0.45 \%$ ethanol solution. The control solution was prepared starting from $45 \%$ ethanol (AppliChem, Darmstadt, Germany) fresh solution and succussed as previously described. This was considered the $1 \times$ control solution. Two serial decimal dilutions/succussions in ultrapure water were applied as reported above to obtain the control $3 \times$ dilution $(\mathrm{Ctrl})$. No filtration was applied at any step. These solutions were used in the culture media at a 1:10 ratio $(0.1 \mathrm{~mL}$ test solution in $0.9 \mathrm{~mL}$ culture medium). Therefore, the final dilution of $D$. rotundifolia was 1000 times greater than that of the ethanolic extract and the ethanol concentration was $0.045 \%$.
\end{abstract}

Phenolic quantification. The total phenolic content of the D. rotundifolia ethanolic extract was determined by the Folin-Ciocalteu assay ${ }^{39}$. Briefly, $50 \mu \mathrm{L}$ of extract at an appropriate dilution was mixed with $155 \mu \mathrm{L}$ of Folin-Ciocalteu reagent diluted 1:10 v/v with water. After $1 \mathrm{~min}, 40 \mu \mathrm{L}$ of $20 \% \mathrm{Na}_{2} \mathrm{CO}_{3}$ solution was added, and the samples were incubated for $30 \mathrm{~min}$ in the dark at $37^{\circ} \mathrm{C}$. The absorbance of each sample was measured at $765 \mathrm{~nm}$. Gallic acid was used as a standard for the calibration curve, and the phenolic content was expressed as gallic acid equivalents. Each determination was repeated three times, and the results are expressed as the mean \pm SD.

Mass spectrometry. A series 1260 HPLC (Agilent Technologies, Waldbronn, Germany) in tandem with a Q-TOF mass spectrometer was used for the present study. The separation was performed on a Zorbax Eclipse XDB $(2.1 \times 150 \mathrm{~mm}, 5 \mu \mathrm{m}$ particle size, Agilent Technologies) with gradient elution. Formic acid $(0.1 \%)$ was solvent $\mathrm{A}$, and methanol was solvent $\mathrm{B}$; the flow rate was $500 \mu \mathrm{L} / \mathrm{min}$. An injection volume of $5 \mu \mathrm{L}$ was used in all experiments. Samples were eluted with a linear gradient from 20 to $95 \%$ of solvent B. The MS analysis was carried out using a model 6540 Accurate-Mass Q-TOF LC/MS (Agilent Technologies, Palo Alto, CA, USA) online with HPLC. QTOF-MS was implemented with an electrospray ion source with Agilent Jet Stream technology operating in negative ionization mode. Data acquisition was performed in full scan mode in the mass range of 


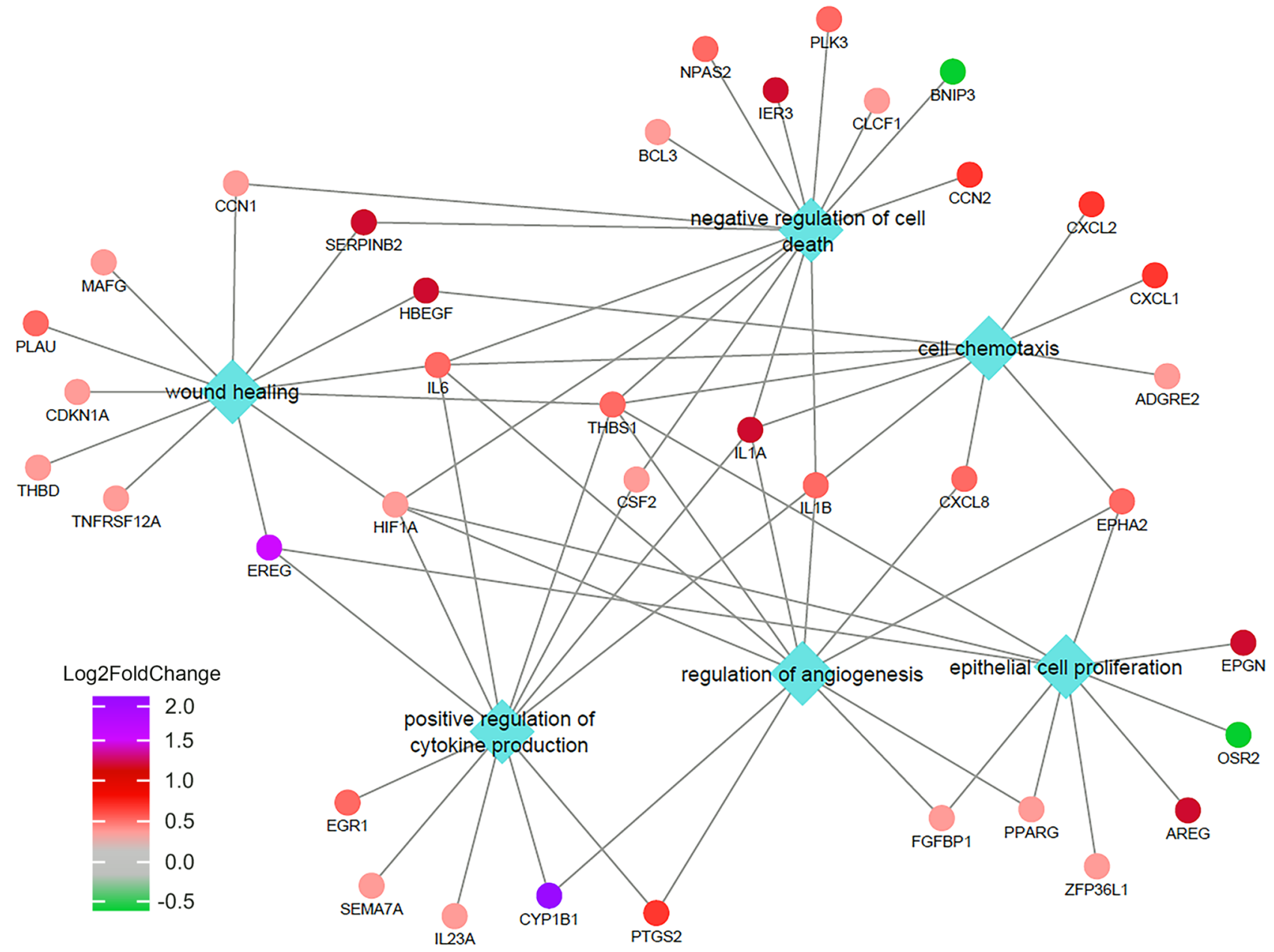

Figure 5. Functional network of enriched biological processes and associated genes. The network was constructed using the selected significant GO terms shown in Fig. 4, which were uploaded into Cytoscape software as described in "Materials and method" section. Diamonds indicate biological processes and circles indicate associated genes.

$100-1000 \mathrm{~m} / \mathrm{z}^{40}$. The standards used were quercetin, ellagic acid (Sigma-Aldrich, Saint Louis, MO, USA), isoquercitrin and hyperoside (HWi, Ruelzheim, Germany).

Cell treatment. 16HBE human bronchial epithelial cells (line 16HBE14o-, kindly provided by Dr Gruenert, University of California, San Francisco) were grown for 1 week in EMEM medium supplemented with 10\% FBS (including $2 \mathrm{mM}$ UltraGlutamine, $100 \mathrm{U} / \mathrm{mL}$ penicillin and $100 \mu \mathrm{g} / \mathrm{mL}$ streptomycin) from cryogenically frozen samples $\left(2 \times 10^{6}\right.$ cells/vial $)$ prepared from the batch culture $(\mathrm{P} 14,14$ th culture passage from the original culture). Fibronectin/collagen/BSA-coated flasks were used ${ }^{41}$. The culture medium was replaced every 3 days. Prior to the treatment, on day 1, cells were seeded in 24 -well plates (uncoated) at a density of $0.4 \times 10^{6}$ cells/well in EMEM medium with $2 \%$ FBS (including $2 \mathrm{mM}$ UltraGlutamine, $100 \mathrm{U} / \mathrm{mL}$ penicillin and $100 \mu \mathrm{g} / \mathrm{mL}$ streptomycin). The plates were incubated until complete adhesion of the cells occurred $(16-20 \mathrm{~h})$. On day 2, the culture medium was replaced by $0.9 \mathrm{~mL}$ of fresh EMEM with $2 \%$ FBS. D. rotundifolia $3 \times$ or Ctrl was added $(0.1 \mathrm{~mL} /$ well). The plates were incubated for $2 \mathrm{~h}, 3 \mathrm{~h}, 6 \mathrm{~h}$ or $24 \mathrm{~h}$ depending on each experimental setting. The final volume was $1 \mathrm{~mL} /$ well. The Ctrl cell cultures were carried out in parallel with those treated with D. rotundifolia for the indicated times in the same culture plates. After the desired incubation period, treated and Ctrl 16HBE cells were collected and subjected to RNA extraction.

Evaluation of cell viability. Cell viability was checked by the cell proliferation reagent WST-1 (Gibco ThermoFisher Scientific). The WST assay evaluates the cell metabolic activities (NADH reductase) by measuring the chemical modification of the WST tetrazolium salt. 16HBE cells were seeded at a density of 50,000 cells/well in 96-well plates and treated for 3 or $24 \mathrm{~h}$ with the D. rotundifolia $3 \times$ or the Ctrl solutions, which were added to the cell culture at a 1/10 volume ratio. After treatment, 1:10 (v/v) prewarmed WST-1 solution was added to the cells, and the plate was incubated for $90 \mathrm{~min}$. The absorbance (OD) of the samples was measured using a Vic- 


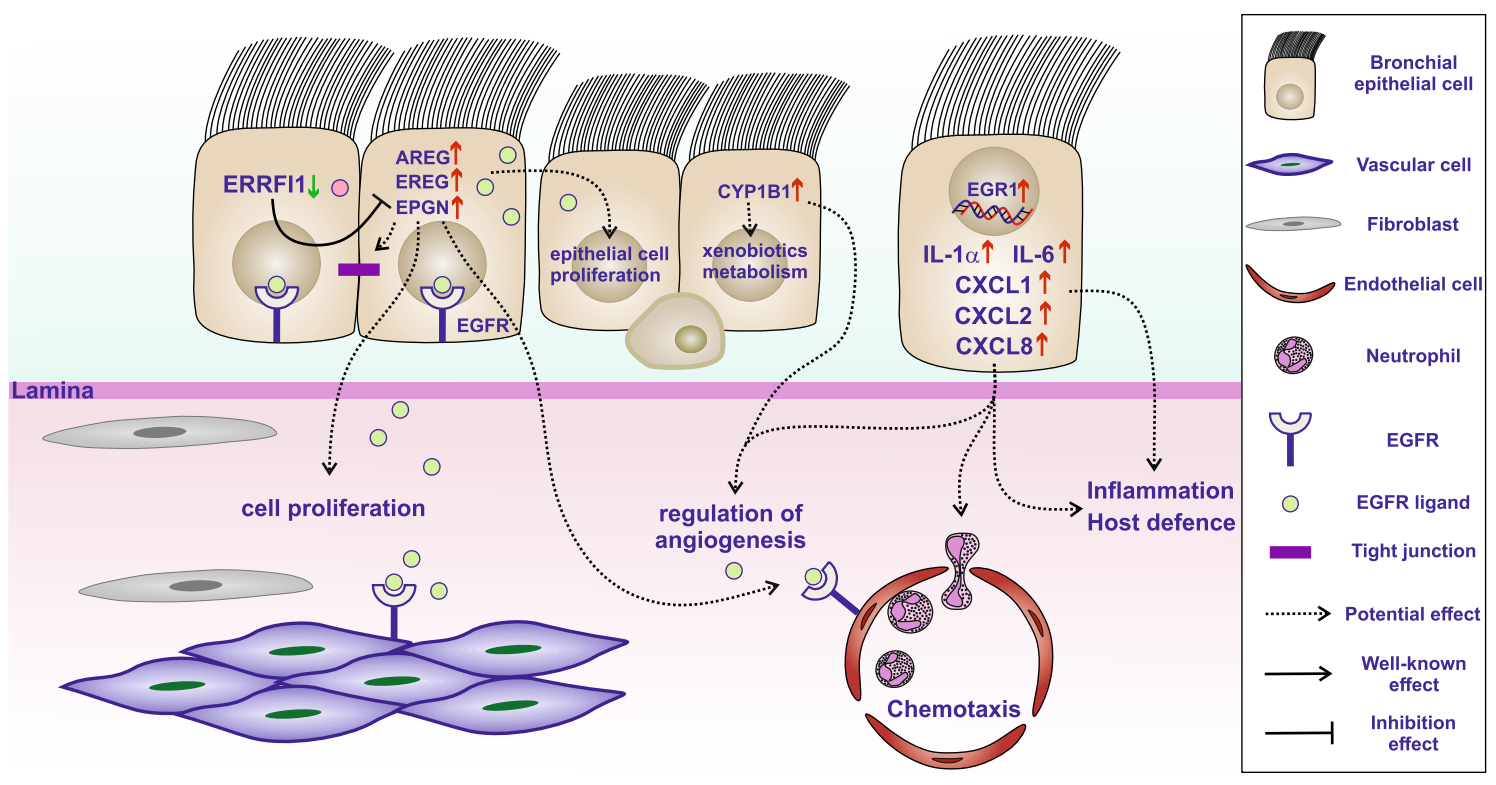

Figure 6. Illustrative graphic summarizing the potential effects of $D$. rotundifolia $3 \times$ on bronchial epithelial cells. The presence of $D$. rotundifolia $3 \times$ induces the expression of epidermal growth factors (AREG, EREG and $E P G N)$, leading to the growth/repair of bronchial epithelial cells and other cells in the bronchial environment. Those genes, which bind to EGFR to accomplish their functions, are regulated by ERFFI1, which is in turn downregulated by $D$. rotundifolia $3 \times$ in the first $3 \mathrm{~h}$. CYP1B1 is highly expressed and is related to the metabolism of xenobiotics and could be involved in the regulation of angiogenesis. Furthermore, inflammatory cytokines (IL-1 $\alpha$ and $I L-6)$ and chemokines (CXCL1, CXCL2 and CXCL8) are induced by D. rotundifolia $3 \times$ and can trigger mild inflammation, increasing chemotaxis and angiogenesis, helping the system in fighting infections.

tor3 multilabel reader (PerkinElmer, Shelton, CT, USA) at $450 \mathrm{~nm}$. Cell viability data were evaluated by t-test statistics (D. rotundifolia $3 \times$ vs Ctrl).

RNA extraction. Total RNA from cultured 16HBE cells was isolated using the RNeasy mini Kit (Qiagen, Venlo, Limburg, Netherlands) according to the manufacturer's instructions. An on-column DNase digestion with the RNase-free DNase kit (Qiagen) was also performed during total RNA isolation to completely remove any possible contaminating DNA. RNA quality and quantity were determined using a Nanodrop 2000 spectrophotometer (Thermo Fisher Scientific, Waltham, Massachusetts, USA) ${ }^{42}$.

RNA sequencing (RNA-seq). RNA samples were processed in the Genomic and Transcriptomic Unit at the Technologic Platform Centre (University of Verona, Italy). Total RNA extracted from 16HBE cells was assessed for quality (integrity) using an RNA 6000 Nano Kit (Agilent, Wokingham, UK). The samples with RNA integrity numbers $>9$ were considered adequate for library preparation. RNA aliquots $(2.5 \mu \mathrm{g})$ were used to isolate poly(A) mRNA for the preparation of a directional Illumina RNA-Seq library using the Illumina TruSeq Stranded mRNA Library Prep Kit (Illumina Inc., San Diego, CA, USA). The quality of the library before the generation of the clusters was checked through the visualization of the DNA fragments in the miniaturized electrophoresis system Tape Station (Agilent D1000 Screen Tape system). The average insert sizes were in the range of 300-370 bp. The libraries were also quantified by qPCR using the KAPA Library Quantification kit (Kapa Biosystems Inc., Woburn, MA, USA). The libraries (differentially labelled) were pooled in equal amounts before sequencing. Sequencing was performed with an Illumina NextSeq 500 (Illumina, CA, USA). The samples were sequenced with a single-end protocol (75 base pairs) with a sequence depth of approximately $30 \mathrm{M}$ reads for the sample. After sequencing, the FastQC High Throughput Sequence QC Report (Version 0.11.8) was used to assess the quality of the sequencing based on the FASTQ files.

Transcript quantification was performed with the high-performance computing server at the Computational Unit of the Technologic Platform Centre (University of Verona, Italy). Transcript quantification was determined from the FASTQ reads using the mapping-based mode of Salmon (Version 0.13.1) ${ }^{43}$ with the following parameters: “-i index -l SR -r name -validateMappings -gcBias". The reference sequence and annotation files were downloaded from the GENCODE repository (Human Release 32, GRCh38.p13) at the following website: https ://www.gencodegenes.org/human/. The output of Salmon was then imported into the RStudio environment ( $\mathrm{R}$ Version 3.5.3; R studio version 1.1.463) using Bioconductor/R package tximport (Version 1.10.10) ${ }^{44}$, which converted data from the transcript level to the gene level during the importing process. Genes with less than 10 reads were discarded from the posterior analysis. Differential expression analysis was performed using the Bioconductor/R package DESeq2 (Version 1.22.2) ${ }^{45}$. After differential analysis, the lfcShrink function in DESeq2 was applied to shrink the log2FoldChanges. Significance values were based on a Wald significance test, and differences in gene expression with an adjusted p-value $<0.05$ (corrected by the Benjamini-Hochberg method) were considered significant. For the RNA-seq analysis of the experiments, in which the cells were treated for $6 \mathrm{~h}$ with 


\begin{tabular}{|l|l|l|}
\hline Gene & Forward & Reverse \\
\hline ADM & AAGTACTTGGCAGATCACTCTC & CCCACTTATTCCACTTCTTTCG \\
\hline AJUBA & CTTTCTACAGTGTCAATGGCTC & CATTGCTTGTAGGATCTTCTCCA \\
\hline AREG & GAGCCGACTATGACTACTCAG & CTTAACTACCTGTTCAACTCTGAC \\
\hline ARRDC3 & GTTTATCACTTCCTGAAAGACCTG & CTCTCAAAGTCATCACAAGCAC \\
\hline CTGF & CCCAGACCCAACTATGATTAGAG & CTCCACAGAATTTAGCTCGGT \\
\hline CXCL2 & TTTATTTATTTGTTGTTTTAGAAG & CTAACTTGGGTTTGACCTAAAAT \\
\hline CXCL8 & AGAGACAGCAGAGCACACAAG & ACACAGTGAGATGGTTCCTTC \\
\hline CYP1B1 & CTGGATTTGGAGAACGTACCG & TCAGGATACCTGGTGAAGAGGA \\
\hline DDIT3 & AGTCATTGCCTTTCTCCTTCG & TGATTCTTCCTCTTCATTTCCAGG \\
\hline DDIT4 & GAGGAAGACACGGCTTACCT & CAGTAGTTCTTTGCCCACCT \\
\hline$D E P P 1$ & CTCATCCATTCTCCTGCCAC & GTGCCAGTCGAGATATAGACC \\
\hline$E G R 1$ & AGCAGCAGCACCTTCAACC & GCAGGCTCCAGGGAAAAG \\
\hline$E P G N$ & ATTCAACGCAATGACAGCAC & GCTATGGGTCCTTCTATGTTGTC \\
\hline$E R E G$ & ACAGCTTTAGTTCAGACAGAAGAC & GCAAACAATAGCCATTCATGTCAG \\
\hline$E R R F I 1$ & CTAATACCACTTGGGCATGCT & AACTTGATCCTCTTCATGTGGTC \\
\hline GAPDH & AACAGCCTCAAGATCATCAGC & GGATGATGTTCTGGAGAGCC \\
\hline HBEGF & CTCATGTTTAGGTACCATAGGAG & CAGTCTGAAATCACCTTGTGTC \\
\hline$I G F B P 3$ & ACACTGAATCACCTGAAGTTCC & AGCTCCACATTAACCTTGCG \\
\hline$I L 1 A$ & AGAGAGGGAGTCATTTCATTGG & ACTCAGAGACACAGATTGATCC \\
\hline$I L 6$ & GGCACTGGCAGAAAACAACC & GCAAGTCTCCTCATTGAATCC \\
\hline$I R S 2$ & CATCGTGAAAGAGTGAAGATCTG & AAACAGCACAATGATGAATGCC \\
\hline JUN & ACCTTATGGCTACAGTAACCC & TTGCTGGACTGGATTATCAGG \\
\hline NCOA7 & GAAGAAGATGGTGGTTCAGAAG & TCAGTGCTATGGAGTTTAGGG \\
\hline NR2F2 & GTTCACCTCAGATGCCTGTG & CAGTAACATATCCCGGATGAGG \\
\hline$P H L D A 1$ & ATCCACATCCACACTCTCATC & CTTCCTCAAGTCCTCAAAACC \\
\hline$P I K 3 C 2 A$ & AGACTCTTGCCATTACAGAATCAG & CTCCAAACAAAGAAGTCACATCAG \\
\hline$P P P 1 R 15 A$ & GGGAAGTCAATTTGCAGATGG & CGGTGTGATGGTGGATAAGAG \\
\hline$S A S H 1$ & TGAAGACGAGGAGAAACCCA & GGTCGCTGTTACTGTCATACTC \\
\hline$S C L 2 A 3$ & GGATGAGCTTTGTCTGTATTGG & CTAAATAGTGAGCAGCGGAGG \\
\hline$S E R P I N B 2$ & GAGGAGAGGAGATTGAAACAATGG & GGGAGAGGAAGAGGTTCTGG \\
\hline TIPARP & CCACAATTCATTCTTCAGGAGAG & CCACCAAGTGTCTGTAAATATGGA \\
\hline
\end{tabular}

Table 5. List of the gene-specific primers used for RT-qPCR.

D. rotundifolia $3 \times$, a $\log 2$ FoldChange cut-off value $(<0.4$ and $>0.4)$ was applied. To associate a function with the differentially expressed genes, functional enrichment analysis was performed using the Bioconductor/R package gprofiler2 (Version 0.1 .7$)^{46}$. The differentially expressed genes were ranked by the adjusted $p$-value significance, and gene ontology (GO) analysis was queried using the "gost" function in gprofiler2 in "ordered" mode and "g_SCS" as correction/statistical method. The list of significant GO terms was used for the construction of the network using Cytoscape software (Version 3.7.2) ${ }^{47}$.

Reverse transcription quantitative real-time PCR (RT-qPCR). Total RNA extracted from 16HBE cells was reverse transcribed into cDNA using the PrimeScript RT reagent Kit (Takara Bio, Kusatsu, Japan), while qPCR was carried out using TB Green Premix Ex Taq (Tli RNase H Plus) (Takara Bio) ${ }^{42}$. The sequences of the gene-specific primers (Thermo Fisher Scientific, Waltham, Massachusetts, USA) used in this study are listed in Table 5. qPCR was performed using a Viia7 Real-time PCR system (Thermo Fisher Scientific). Data were calculated by Q-Gene software (http://www.gene-quantification.de/download.html) and expressed as the mean normalized expression (MNE) units after GAPDH normalization ${ }^{42}$. Statistical evaluation was performed by twoway ANOVA followed by Bonferroni's post hoc test. Values of $\mathrm{p}<0.05$ were considered statistically significant.

Ethics approval and consent to participate. Not applicable, as the study did not involve patients, volunteers or animals.

\section{Data availability}

The raw and processed RNA-seq data are available in the public GEO database (https://www.ncbi.nlm.nih.gov/ geo/) under the accession number GSE144215.

Received: 20 May 2020; Accepted: 5 January 2021

Published online: 27 January 2021 


\section{References}

1. Sevar, R. Audit of outcome in 455 consecutive patients treated with homeopathic medicines. Homeopathy 94, 215-221 (2005).

2. Haidvogl, M. et al. Homeopathic and conventional treatment for acute respiratory and ear complaints: A comparative study on outcome in the primary care setting. BMC Complement. Altern. Med. 7, 7 (2007).

3. Saha, S. K., Roy, S. \& Khuda-Bukhsh, A. R. Ultra-highly diluted plant extracts of Hydrastis canadensis and Marsdenia condurango induce epigenetic modifications and alter gene expression profiles in HeLa cells in vitro. J. Integr. Med. 13, 400-411 (2015).

4. Danno, K. et al. Management of the early symptoms of influenza-like illnesses and ear, nose and throat (ENT) disorders by pharmacists. Homeopathy 103, 239-249 (2014).

5. Zanasi, A. et al. Homeopathic medicine for acute cough in upper respiratory tract infections and acute bronchitis: A randomized, double-blind, placebo-controlled trial. Pulm. Pharmacol. Ther. 27, 102-108 (2014).

6. Jacobs, J. \& Taylor, J. A. A randomized controlled trial of a homeopathic syrup in the treatment of cold symptoms in young children. Complement. Ther. Med. 29, 229-234. https://doi.org/10.1016/j.ctim.2016.10.013 (2016).

7. Frass, M. et al. Adjunctive homeopathic treatment in patients with severe sepsis: A randomized, double-blind, placebo-controlled trial in an intensive care unit. Homeopathy 94, 75-80 (2005).

8. Boericke, W. Pocket Manual of Homeopathic Materia Medica \& Repertory (1997).

9. Allaert, F.-A., Villet, S., Vincent, S. \& Sauve, L. Observational study on the dispensing of cough syrups to children with acute cough by community pharmacists in France. Minerva Pediatr. 70, 117-126 (2018).

10. Voß, H. W., Michalsen, A. \& Brünjes, R. Efficacy and tolerability of a complex homeopathic drug in children suffering from dry cough-A double-blind, placebo-controlled, clinical trial. Drug Res. (Stuttg.) 68, 444-449 (2018).

11. Zanasi, A. et al. Does additional antimicrobial treatment have a better effect on URTI cough resolution than homeopathic symptomatic therapy alone? A real-life preliminary observational study in a pediatric population. Multidiscip. Respir. Med. 10, 25. https ://doi.org/10.1186/s40248-015-0022-3 (2015).

12. Bordes, L. \& Dorfman, P. Evaluation de l'activité antitussive du siropDrosetux: Etude en double aveugle versus placebo. Les Cah. d'otorhinolaringol. 21, 731-734 (1986).

13. Zehl, M. et al. Identification and quantification of flavonoids and ellagic acid derivatives in therapeutically important Drosera species by LC-DAD, LC-NMR, NMR, and LC-MS. Anal. Bioanal. Chem. 400, 2565-2576 (2011).

14. Paper, D. H., Karall, E., Kremser, M. \& Krenn, L. Comparison of the antiinflammatory effects of Drosera rotundifolia and Drosera madagascariensis in the HET-CAM assay. Phyther. Res. 19, 323-326 (2005).

15. Mattioli, V. et al. Dietary flavonoids and respiratory diseases: A population-based multi-case-control study in Italian adults. Public Health Nutr. 23, 2548-2556. https://doi.org/10.1017/S1368980019003562 (2020).

16. Krenn, L. et al. In vitro antispasmodic and anti-inflammatory effects of Drosera rotundifolia. Arzneimittelforschung 54, 402-405 (2004).

17. Carsin, A. et al. Bronchial epithelium in children: A key player in asthma. Eur. Respir. Rev. 25, 158-169 (2016).

18. Heijink, I. H., Brandenburg, S. M., Postma, D. S. \& van Oosterhout, A. J. M. Cigarette smoke impairs airway epithelial barrier function and cell-cell contact recovery. Eur. Respir. J. 39, 419-428 (2012).

19. Awatade, N. T. et al. Human primary epithelial cell models: Promising tools in the era of cystic fibrosis personalized medicine. Front. Pharmacol. 9, 1429 (2018).

20. Blume, C. \& Davies, D. E. In vitro and ex vivo models of human asthma. Eur. J. Pharm. Biopharm. 84, 394-400 (2013).

21. Mayer, A. K., Bartz, H., Fey, F., Schmidt, L. M. \& Dalpke, A. H. Airway epithelial cells modify immune responses by inducing an anti-inflammatory microenvironment. Eur. J. Immunol. 38, 1689-1699 (2008).

22. Riechelmann, H. et al. Differential response of mono mac 6, BEAS-2B, and jurkat cells to indoor dust. Environ. Health Perspect. 115, 1325-1332 (2007).

23. Fisher, P. What is homeopathy? An introduction. Front. Biosci. (Elite Ed.) 4, 1669-1682 (2012).

24. Bellavite, P. et al. Cell sensitivity, non-linearity and inverse effects. Homeopathy 104, 139-160 (2015).

25. Marotti, I. et al. Transcriptome profiling of wheat seedlings following treatment with ultrahigh diluted arsenic trioxide. Evid.-based Complement. Altern. Med. 2014, 851263 (2014).

26. Marzotto, M. et al. Extreme sensitivity of gene expression in human SH-SY5Y neurocytes to ultra-low doses of Gelsemium sempervirens. BMC Complement. Altern. Med. 14, 104 (2014).

27. Bigagli, E., Luceri, C., Dei, A., Bernardini, S. \& Dolara, P. Effects of extreme dilutions of Apis mellifica preparations on gene expression profiles of human cells. Dose-Response 14, 1-7 (2016).

28. Lagunin, A. A. et al. Combined network pharmacology and virtual reverse pharmacology approaches for identification of potential targets to treat vascular dementia. Sci. Rep. 10, 257 (2020).

29. Fukushima, K. et al. Drosera rotundifolia and Drosera tokaiensis suppress the activation of HMC-1 human mast cells. J. Ethnopharmacol. 125, 90-96 (2009).

30. Paper, D. H., Karall, E., Kremser, M. \& Krenn, L. Comparison of the antiinflammatory effects of Drosera rotundifolia and Drosera madagascariensis in the HET-CAM assay. Phytother. Res. 19, 323-326 (2005).

31. Yang, Y., Jiang, G., Zhang, P. \& Fan, J. Programmed cell death and its role in inflammation. Mil. Med. Res. 2, 12 (2015).

32. Marin, N. D., Dunlap, M. D., Kaushal, D. \& Khader, S. A. Friend or foe: The protective and pathological roles of inducible bronchusassociated lymphoid tissue in pulmonary diseases. J. Immunol. 202, 2519-2526 (2019).

33. Bellavite, P., Ortolani, R., Pontarollo, F., Pitari, G. \& Conforti, A. Immunology and homeopathy. 5. The rationale of the 'Simile'. Evid.-Based Complement. Altern. Med. 4, 149-163 (2007).

34. Bell, I. R. The complexity of the homeopathic healing response part 1: The role of the body as a complex adaptive system in simillimum-initiated recovery from disease. Homeopathy. https://doi.org/10.1055/s-0039-1694998 (2019).

35. Bell, I. R. The complexity of the homeopathic healing response part 2: The role of the homeopathic simillimum as a complex system in initiating recovery from disease. Homeopathy. https://doi.org/10.1055/s-0039-1694999 (2019).

36. Peiseler, M. \& Kubes, P. More friend than foe: The emerging role of neutrophils in tissue repair. J. Clin. Investig. 129, 2629-2639 (2019).

37. Tang, Y. et al. CYP1B1 expression promotes the proangiogenic phenotype of endothelium through decreased intracellular oxidative stress and thrombospondin-2 expression. Blood 113, 744-754 (2009).

38. Palenski, T. L., Gurel, Z., Sorenson, C. M., Hankenson, K. D. \& Sheibani, N. Cyp1B1 expression promotes angiogenesis by suppressing NF- $\kappa$ B activity. Am. J. Physiol. Physiol. 305, C1170-C1184 (2013).

39. Singleton, V. L. \& Rossi, J. A. Colorimetry of total phenolics with phosphomolybdic-phosphotungstic acid reagents. Am. J. Enol. Vitic. 16, 144-158 (1965).

40. Gottardo, R. et al. Screening for synthetic cannabinoids in hair by using LC-QTOF MS: A new and powerful approach to study the penetration of these new psychoactive substances in the population. Med. Sci. Law 54, 22-27 (2014).

41. Lechner, J. F. \& Laveck, M. A. A serum-free method for culturing normal human bronchial epithelial cells at clonal density. J. Tissue Cult. Methods 9, 43-48. https://doi.org/10.1007/BF01797773 (1985).

42. Arruda-Silva, F. et al. Human neutrophils produce CCL23 in response to various TLR-agonists and TNFa. Front. Cell. Infect. Microbiol. 7, 176 (2017). 
43. Patro, R., Duggal, G., Love, M. I., Irizarry, R. A. \& Kingsford, C. Salmon provides fast and bias-aware quantification of transcript expression. Nat. Methods 14, 417-419 (2017).

44. Soneson, C., Love, M. I. \& Robinson, M. D. Differential analyses for RNA-seq: transcript-level estimates improve gene-level inferences [version 2; peer review: 2 approved]. F1000Research 4, 1521 (2016).

45. Love, M. I., Huber, W. \& Anders, S. Moderated estimation of fold change and dispersion for RNA-seq data with DESeq2. Genome Biol. 15, 550 (2014).

46. Raudvere, U. et al. g:Profiler: A web server for functional enrichment analysis and conversions of gene lists (2019 update). Nucleic Acids Res. 47, W191-W198 (2019).

47. Shannon, P. et al. Cytoscape: A software environment for integrated models of biomolecular interaction networks. Genome Res. 13, 2498-2504 (2003).

\section{Acknowledgements}

The authors acknowledge Dr. Shahram Shahabi from Standard Homeopathic Company for providing the D. rotundifolia ethanolic extract and for valuable discussion regarding the manuscript. This work was supported by a grant from Standard Homeopathic Company, Los Angeles (USA) to the University of Verona, Department of Medicine. The funder contributed to the costs of materials, equipment and two post-doctoral scholarships. The funder did not play any role in the experiments, the analysis of results or data disclosure. The authors acknowledge the Centro Piattaforme Tecnologiche dell'Università degli Studi di Verona for the technical contribution in the RNA-seq and Mass Spectrometry experiments.

\section{Author contributions}

F.A.S. and M.M. executed the experiments, analysed the results and wrote the manuscript. P.B. supervised the research program, the results and the writing of the manuscript. All authors reviewed the manuscript.

\section{Competing interests}

The authors declare no competing interests.

\section{Additional information}

Correspondence and requests for materials should be addressed to F.A.-S.

Reprints and permissions information is available at www.nature.com/reprints.

Publisher's note Springer Nature remains neutral with regard to jurisdictional claims in published maps and institutional affiliations.

(c) (i) Open Access This article is licensed under a Creative Commons Attribution 4.0 International License, which permits use, sharing, adaptation, distribution and reproduction in any medium or format, as long as you give appropriate credit to the original author(s) and the source, provide a link to the Creative Commons licence, and indicate if changes were made. The images or other third party material in this article are included in the article's Creative Commons licence, unless indicated otherwise in a credit line to the material. If material is not included in the article's Creative Commons licence and your intended use is not permitted by statutory regulation or exceeds the permitted use, you will need to obtain permission directly from the copyright holder. To view a copy of this licence, visit http://creativecommons.org/licenses/by/4.0/.

(C) The Author(s) 2021 